\title{
First Total Synthesis of Antitumor Natural Product (+)- and (-)-Pericosine A:
}

\section{Determination of Absolute Stereo Structure}

\section{Yoshihide Usami,* Isao Takaoka, Hayato Ichikawa, Yusuke Horibe, Syunsuke Tomiyama, Misako Ohtsuka, Yumi Imanishi and Masao Arimoto}

Osaka University of Pharmaceutical Sciences, 4-20-1 Nasahara, Takatsuki, Osaka 569-1094, Japan

\section{Supporting Information}

(56 pages)

\section{Table Contents}

A. General Experimental Methods

B. Copies of ${ }^{1} \mathrm{H}$ - and ${ }^{13} \mathrm{C}-\mathrm{NMR}$ spectra of new compounds and synthesized (-)-pericosine A 4' and 30

\section{A. General Experimental Methods}

NMR spectra were recorded at $27 \mathrm{C}$ in $\mathrm{CDCl}_{3}$ with tetramethylsilane (TMS) as internal standard. Melting points are uncorrected. HPLC analyses were performed with a Shimazu Shimpack ODS Prep-SIL column (20 mm internal diameter x $250 \mathrm{~mm}$ length). Liquid column chromatography was conducted over silica gel (Nacalai, silica gel 60, mesh 70-230 or 230-400). Analytical TLC was performed on precoated Merck aluminum sheets (DC-Alufolien Kieselgel $60 \mathrm{~F}_{254}$ ), and compounds were detected by spraying an ethanol solution of phosphomolybdic acid, followed by heating. Dry THF was distilled over sodium benzophenone ketyl under argon atmosphere. 


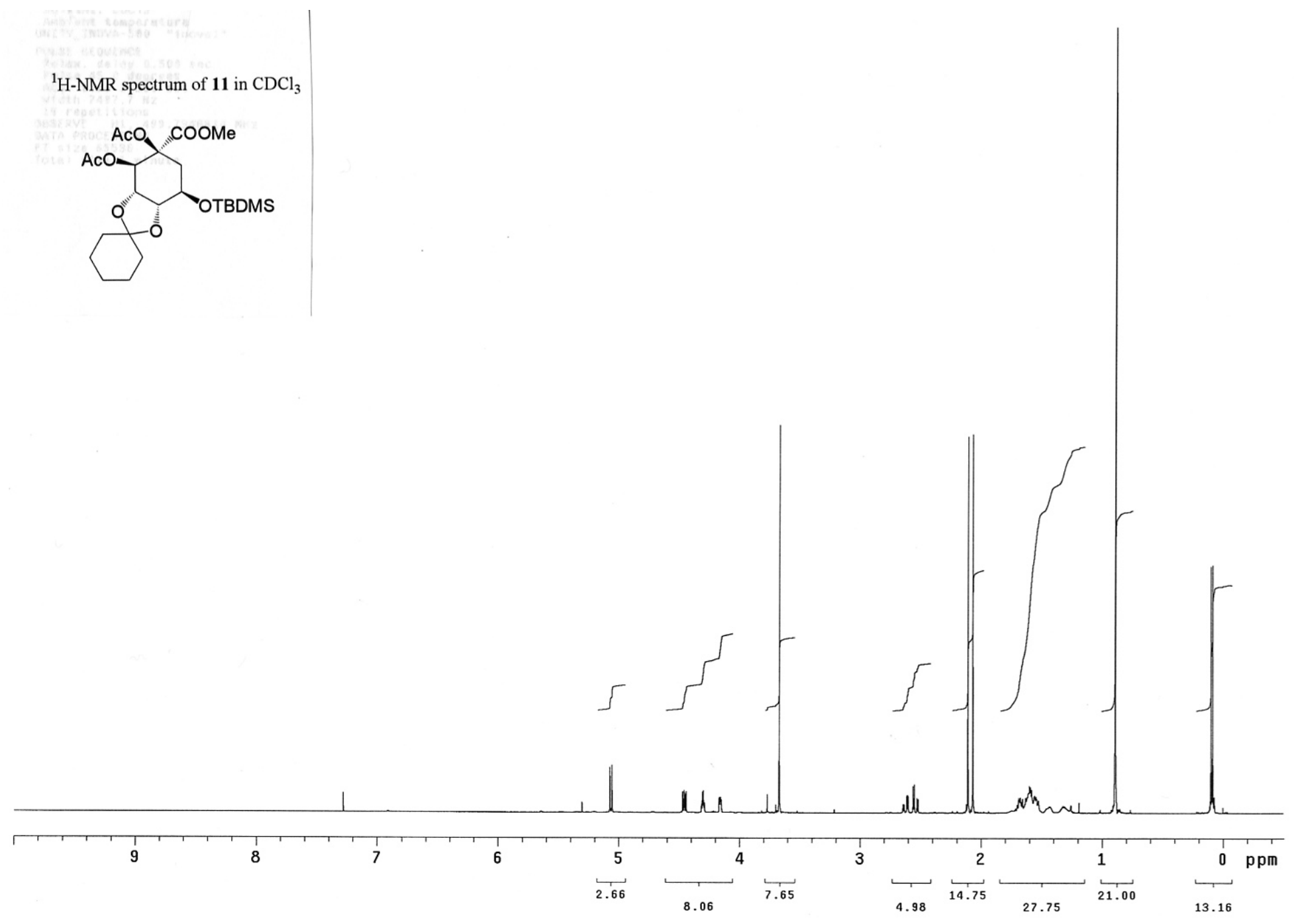

$500 \mathrm{MHz}$ 
${ }^{13} \mathrm{C}-\mathrm{NMR}$ spectrum of $\mathbf{1 1}$ in $\mathrm{CDCl}_{3}$
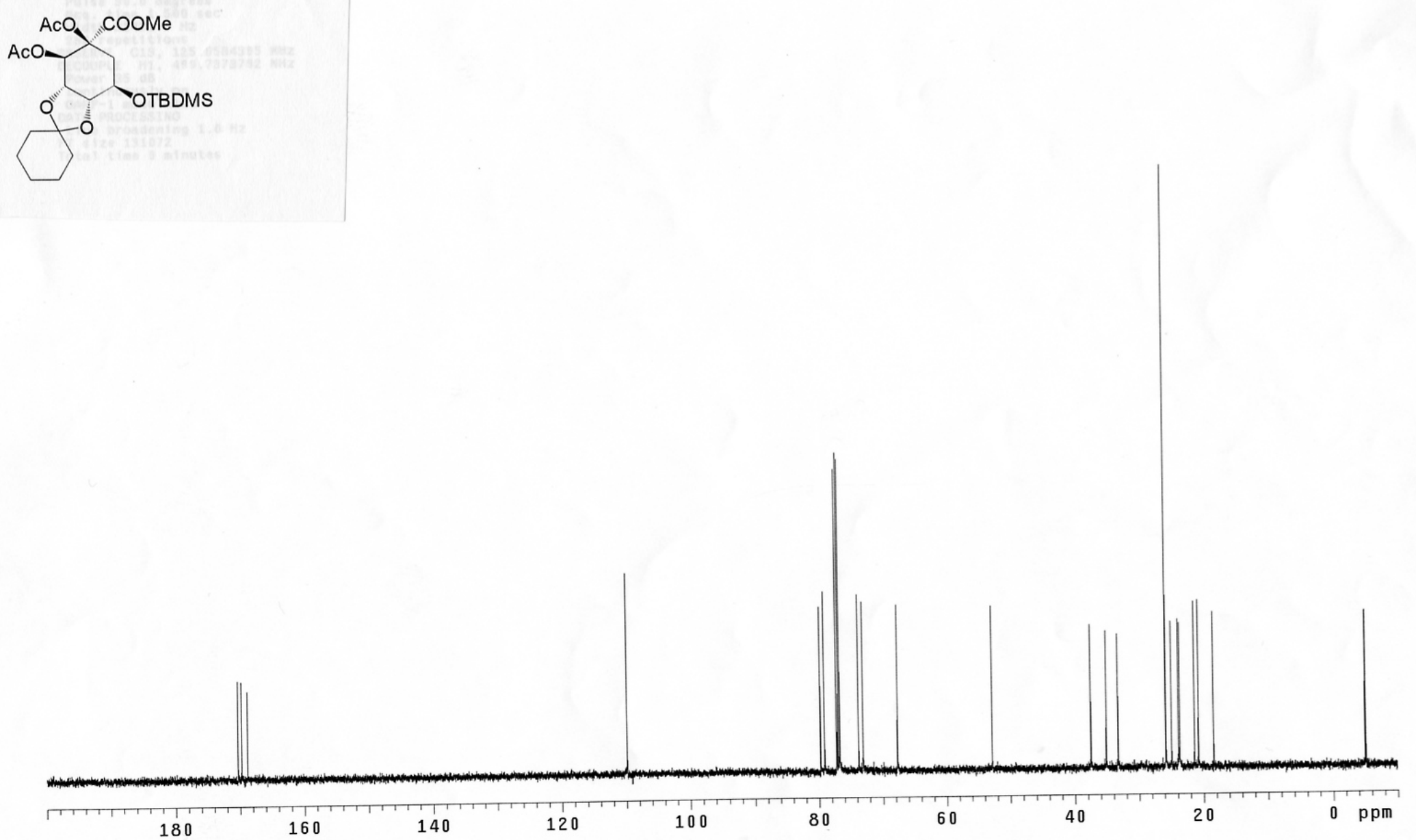

125.6MHz 


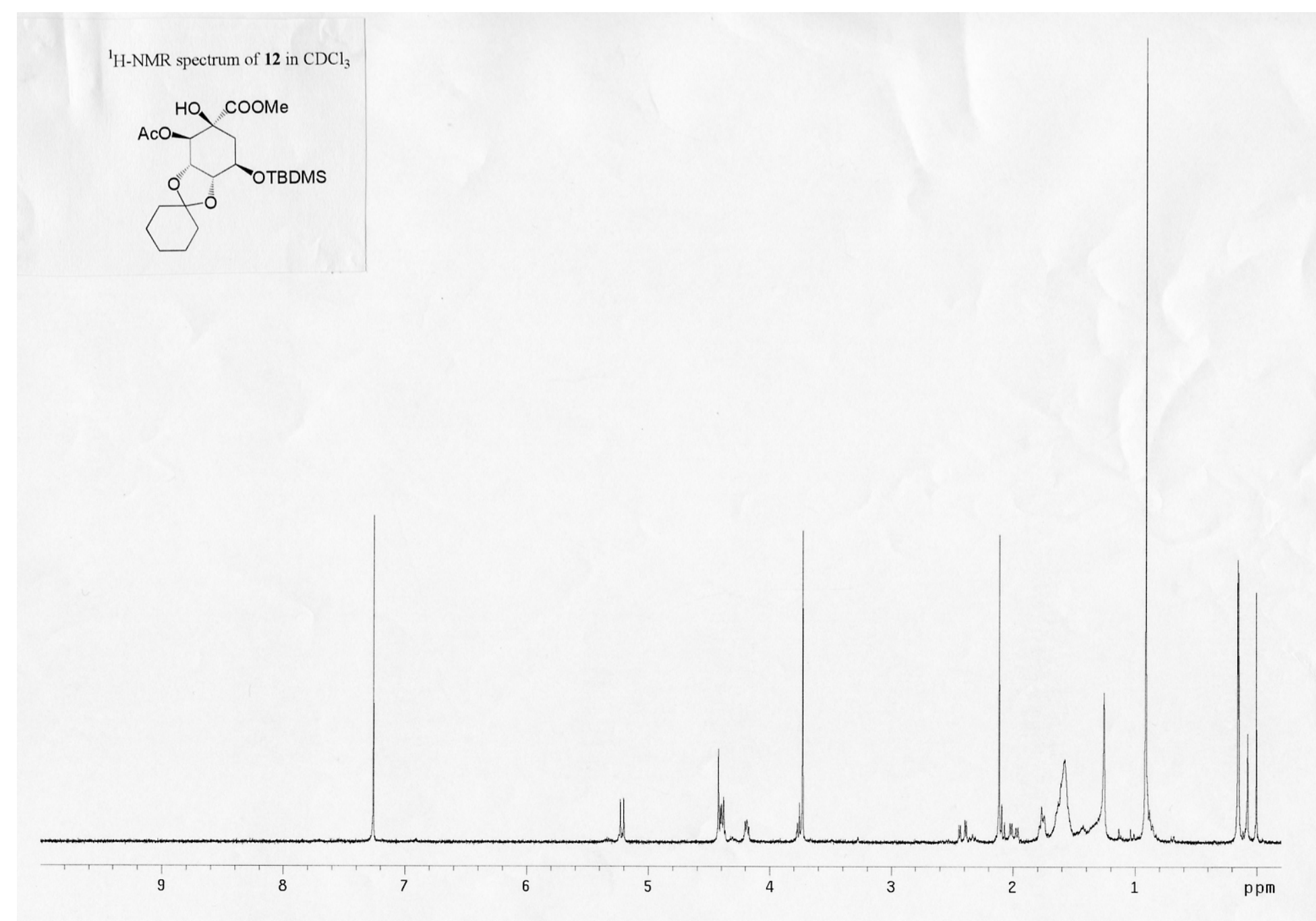

$300 \mathrm{MHz}$ 


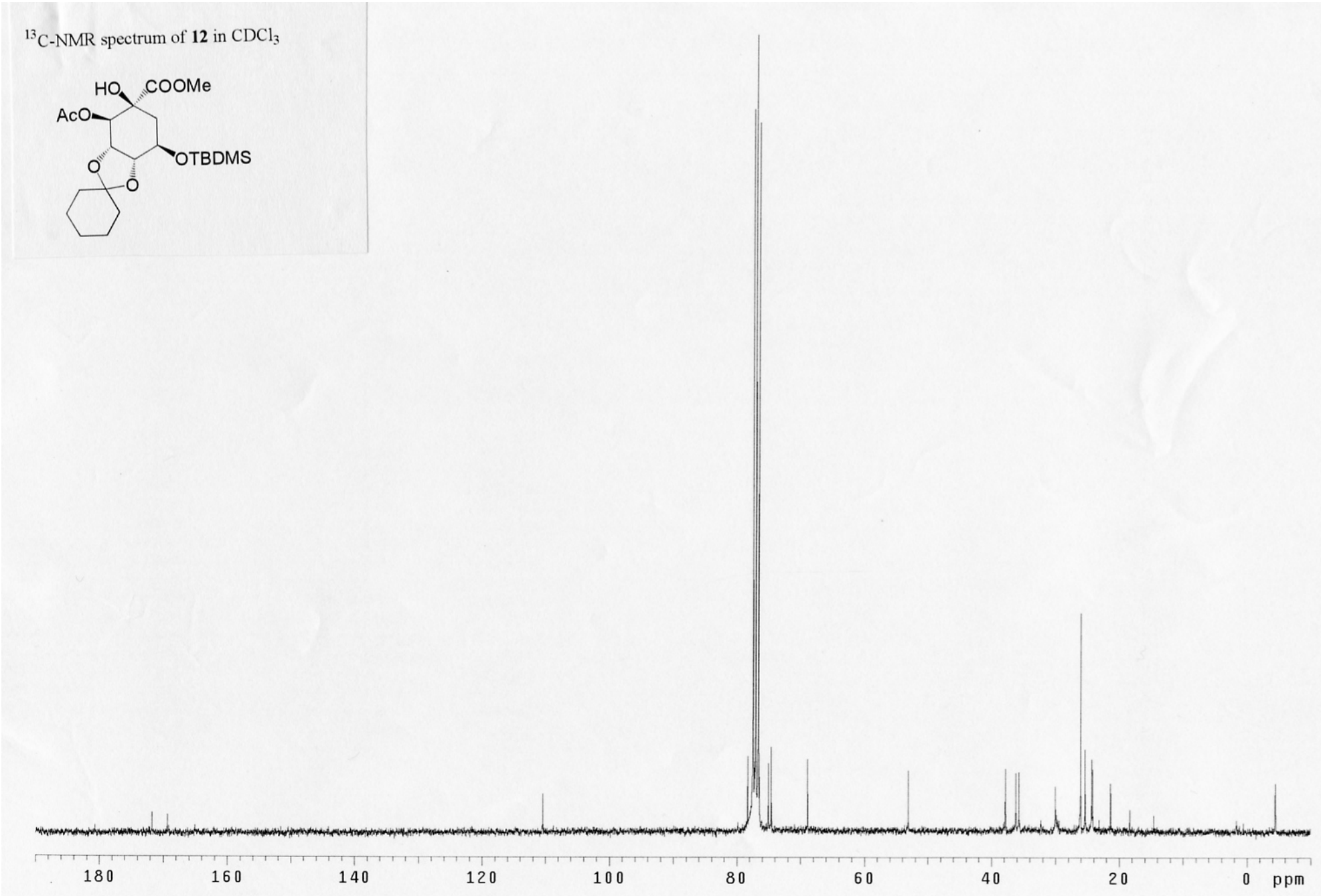

$75 \mathrm{MHz}$ 


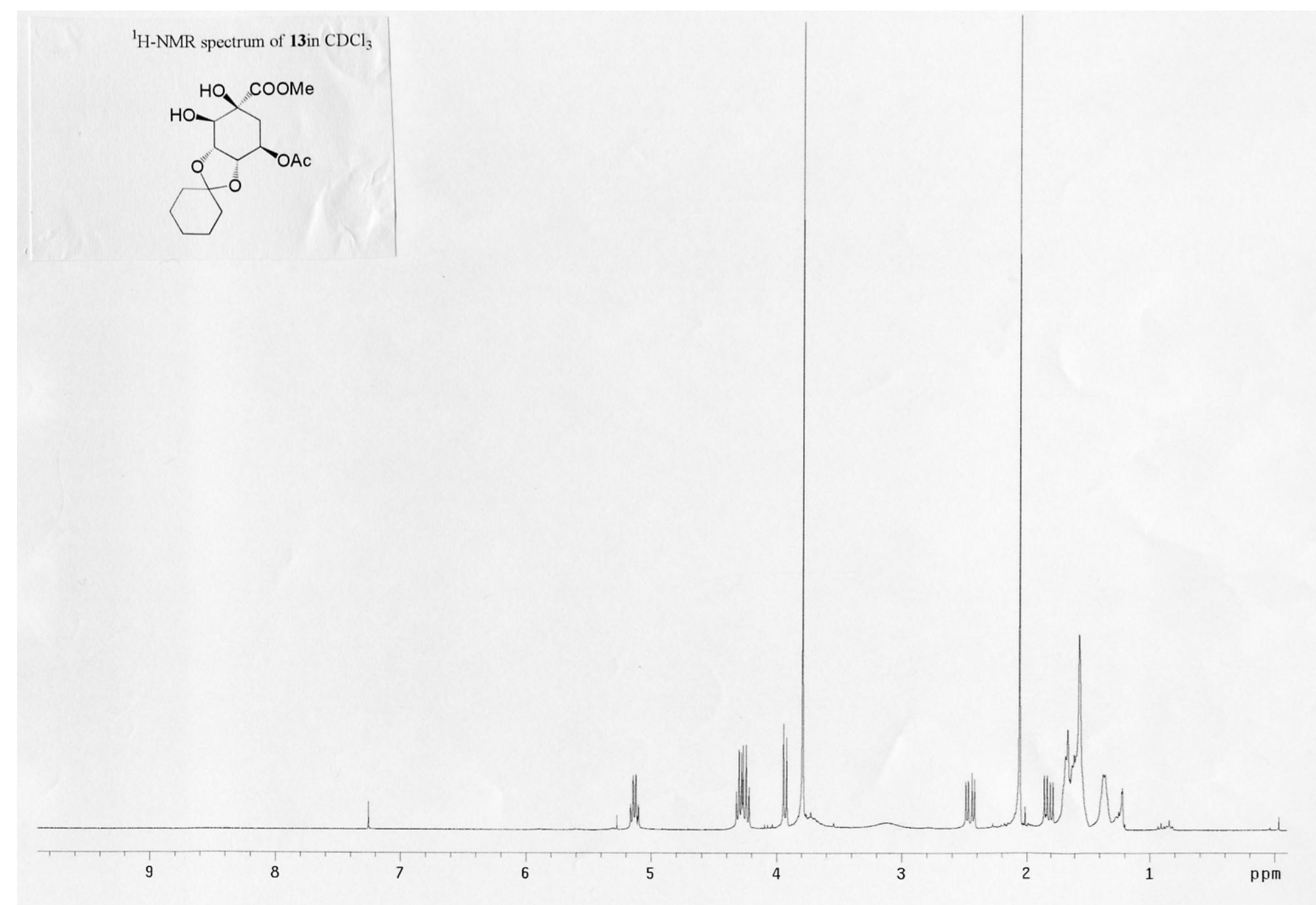

$300 \mathrm{MHz}$ 


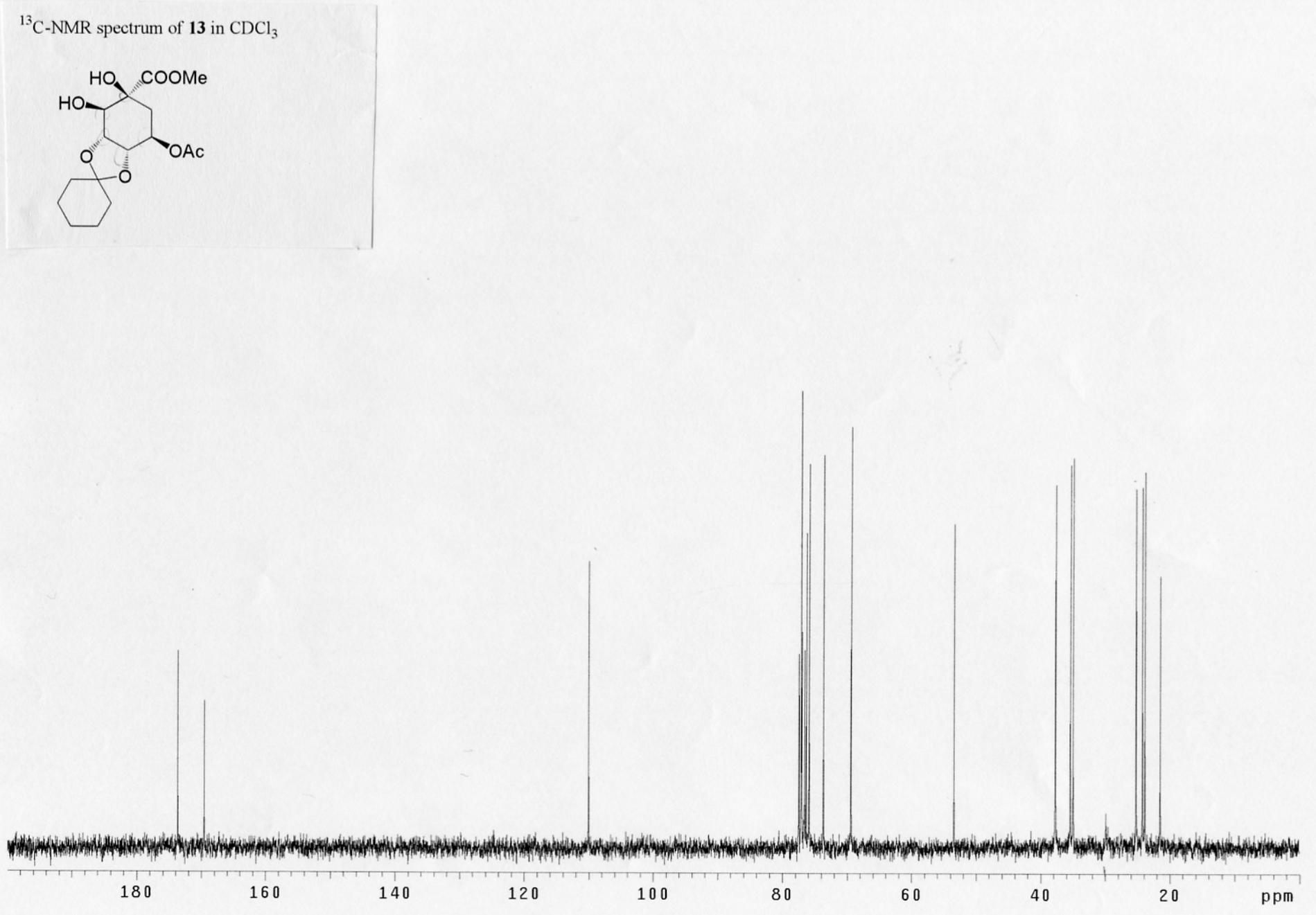

$75 \mathrm{MHz}$ 


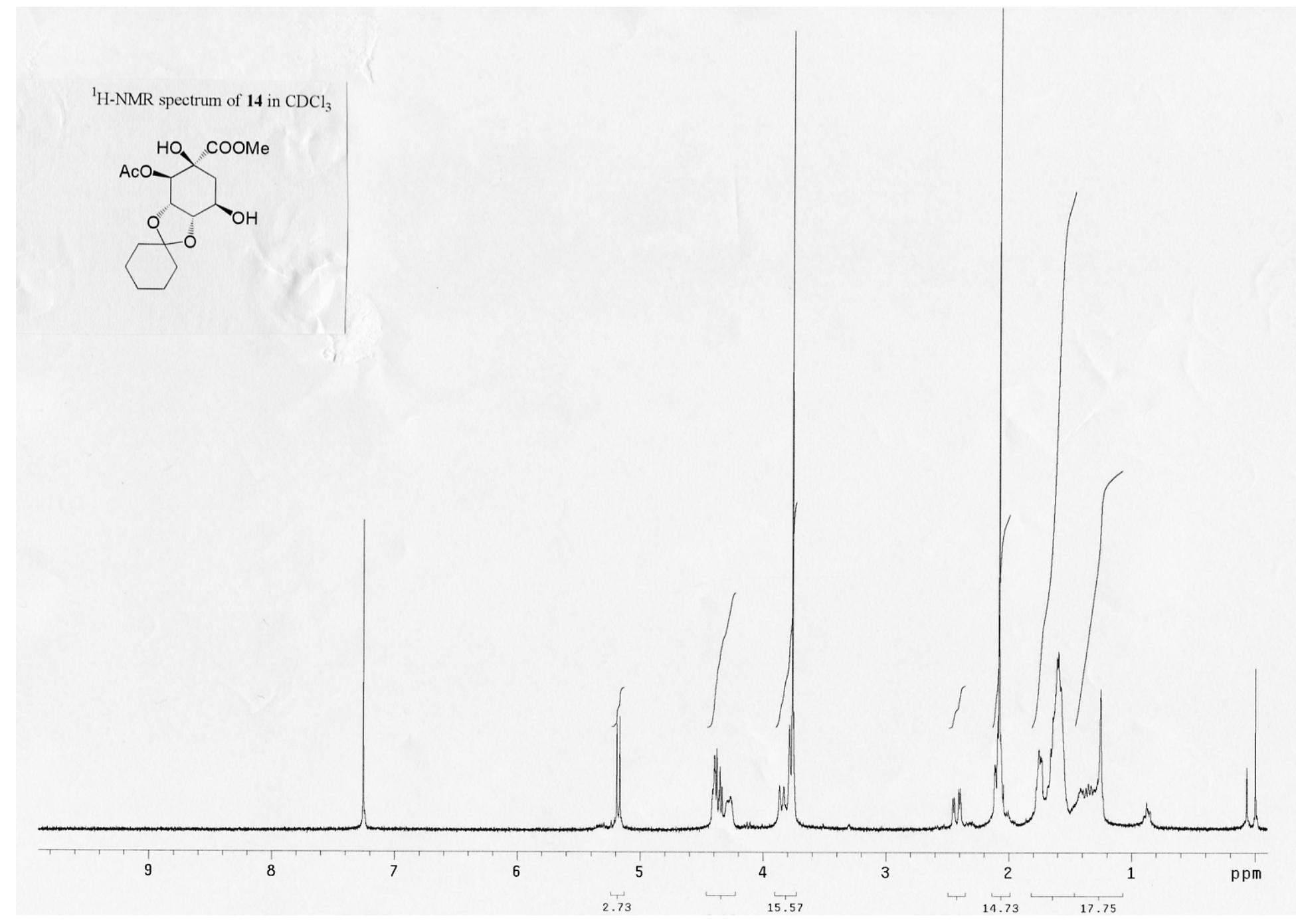

$300 \mathrm{MHz}$ 


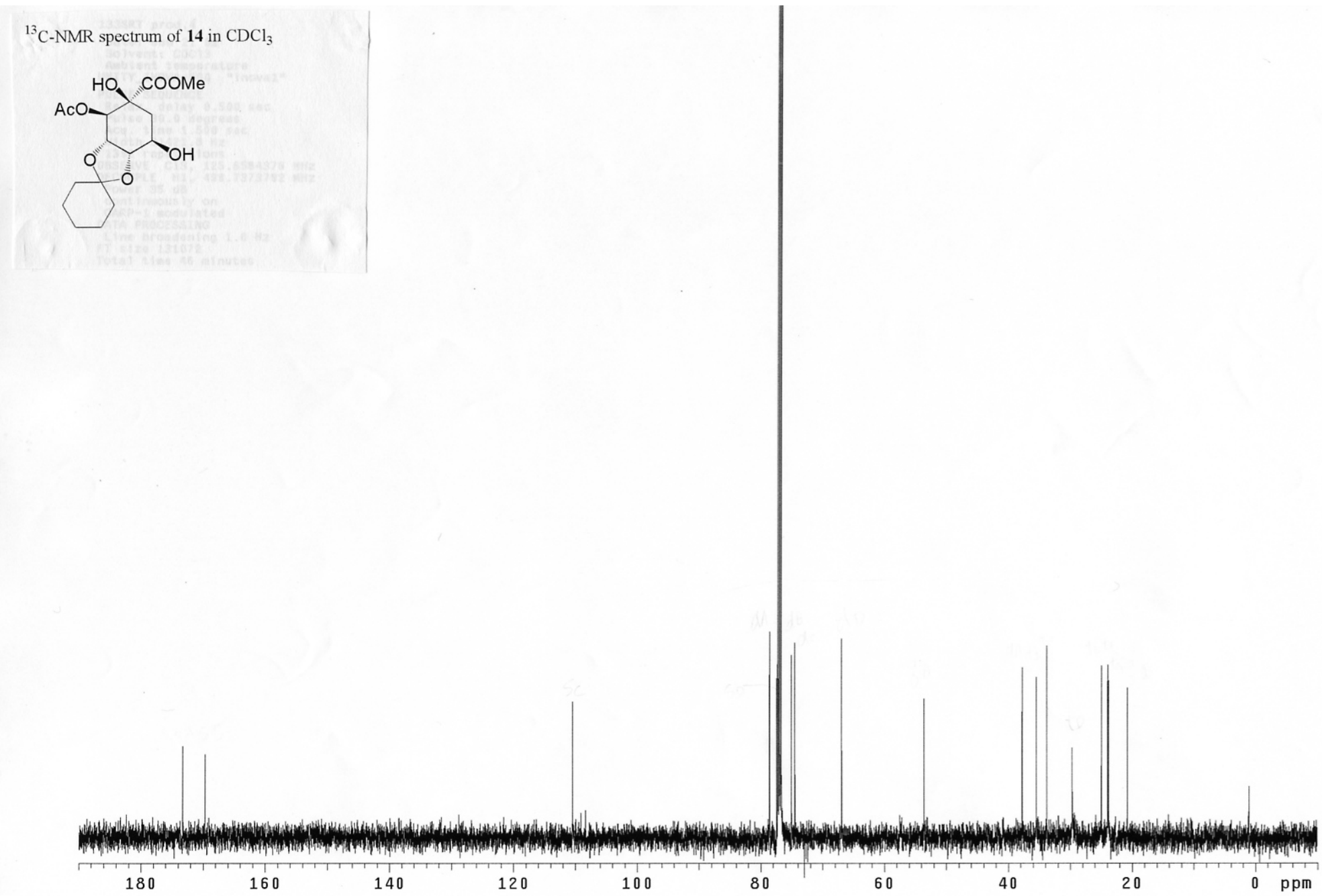

$75 \mathrm{MHz}$ 


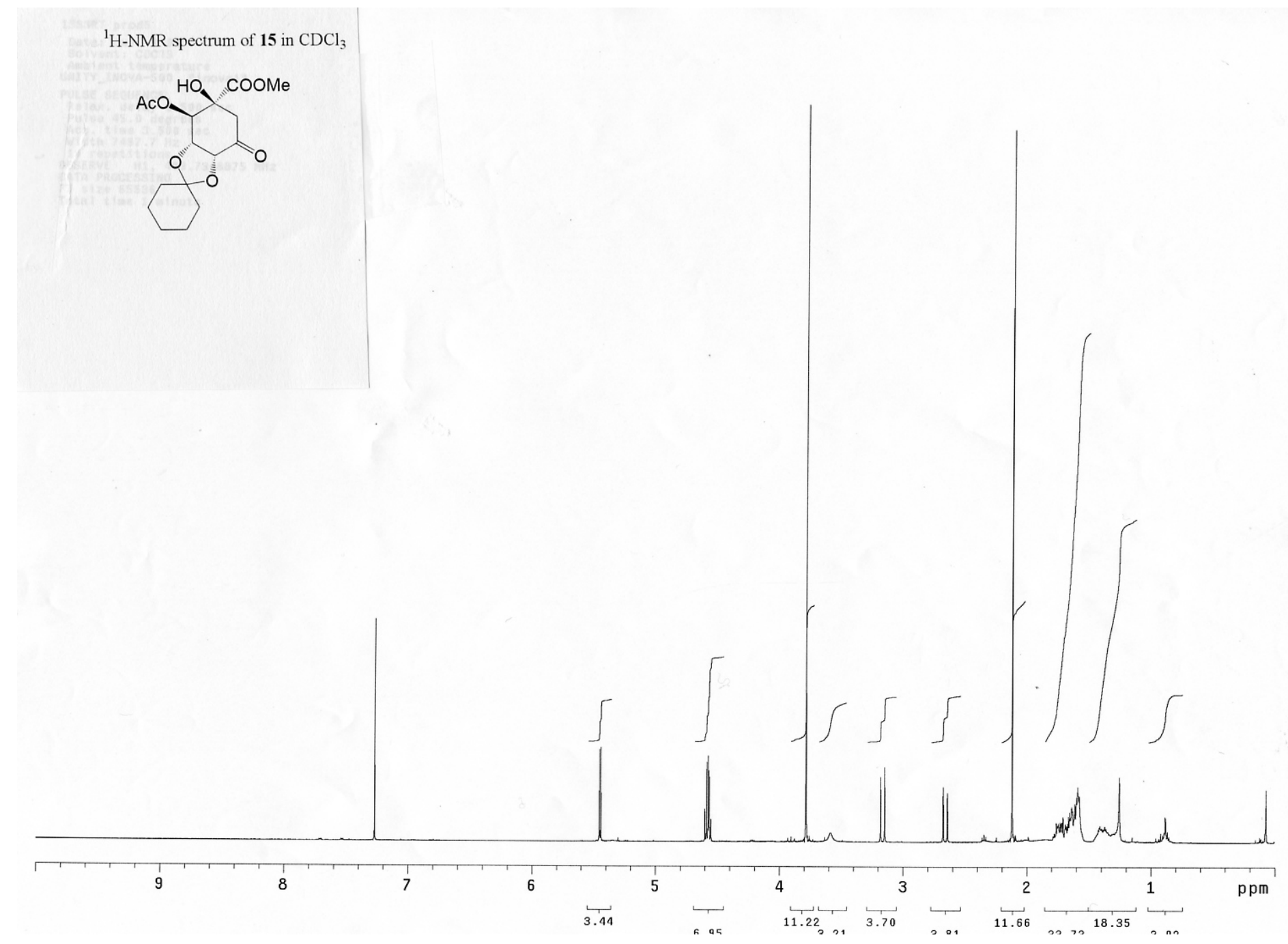

$500 \mathrm{MHz}$ 
133SRT prod5

${ }^{13} \mathrm{C}-\mathrm{NMR}$ spectrum of $\mathbf{1 5}$ in $\mathrm{CDCl}$

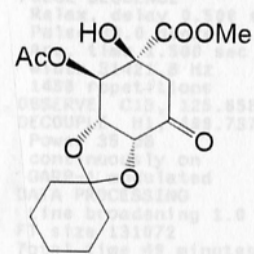

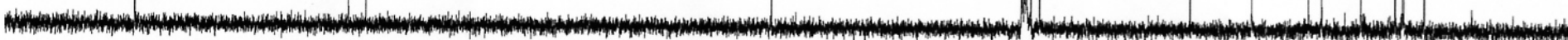

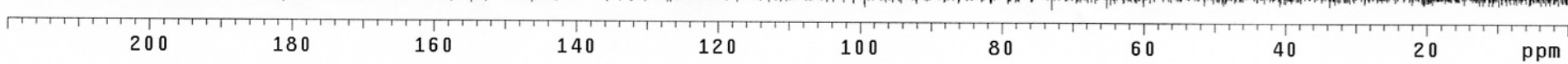

$125.6 \mathrm{MHz}$ 


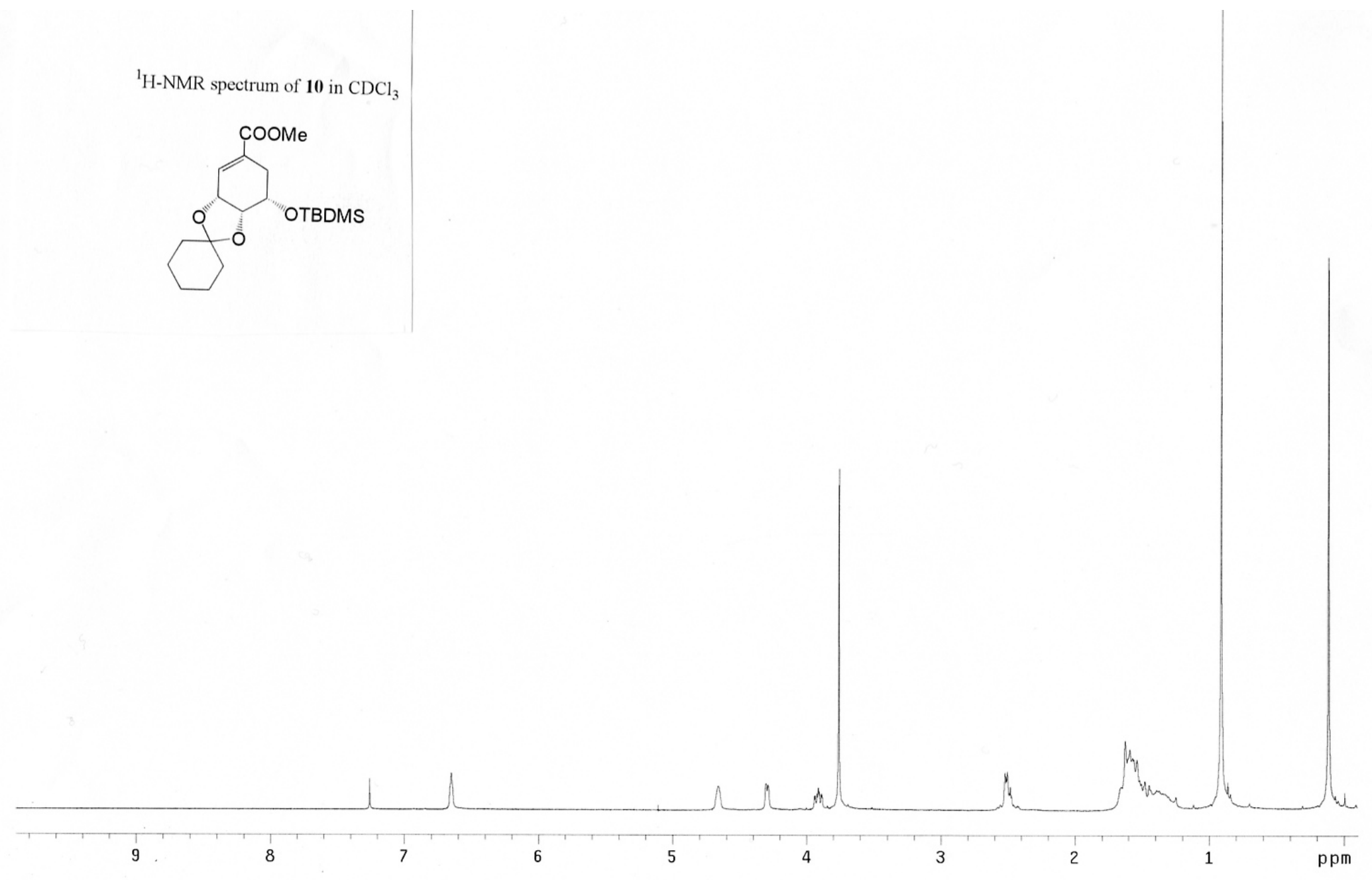

$300 \mathrm{MHz}$ 


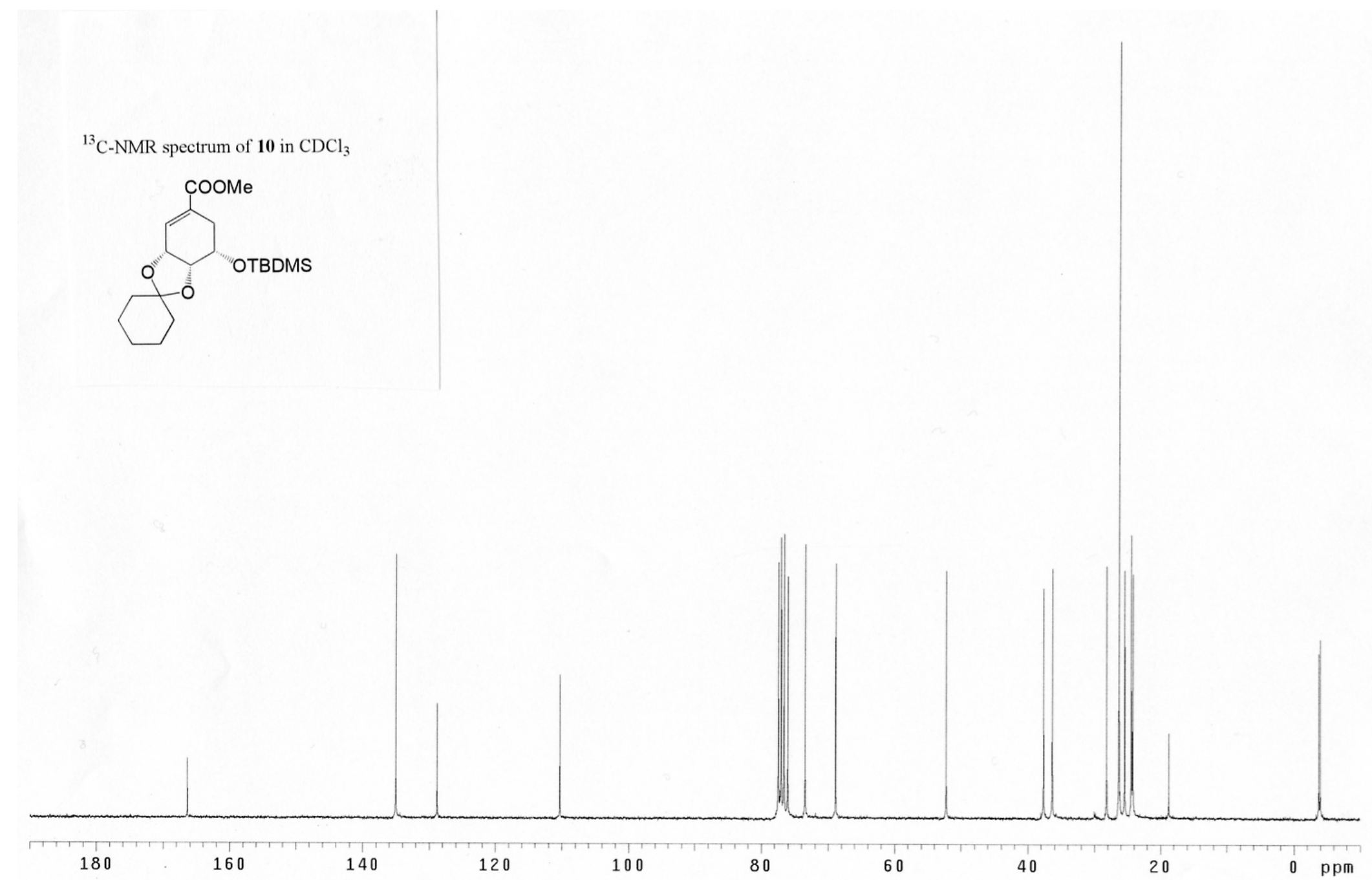

$75 \mathrm{MHz}$ 
13354106

Date: Nov 1303
Solvent: CDC 13

Ambient temperature
UNITY_TNOVA-500 "inova1"

PULSE SEOUENCE
Re elax. de a a $5.000 \mathrm{sec}$
Pulse

Puce time $3.500 \mathrm{sec}$
Acy

OBSERVE

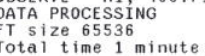

${ }^{1} \mathrm{H}$-NMR spectrum of $\mathbf{8}$ in $\mathrm{CDCl}_{3}$,

HO COOMe

o OTBDMS

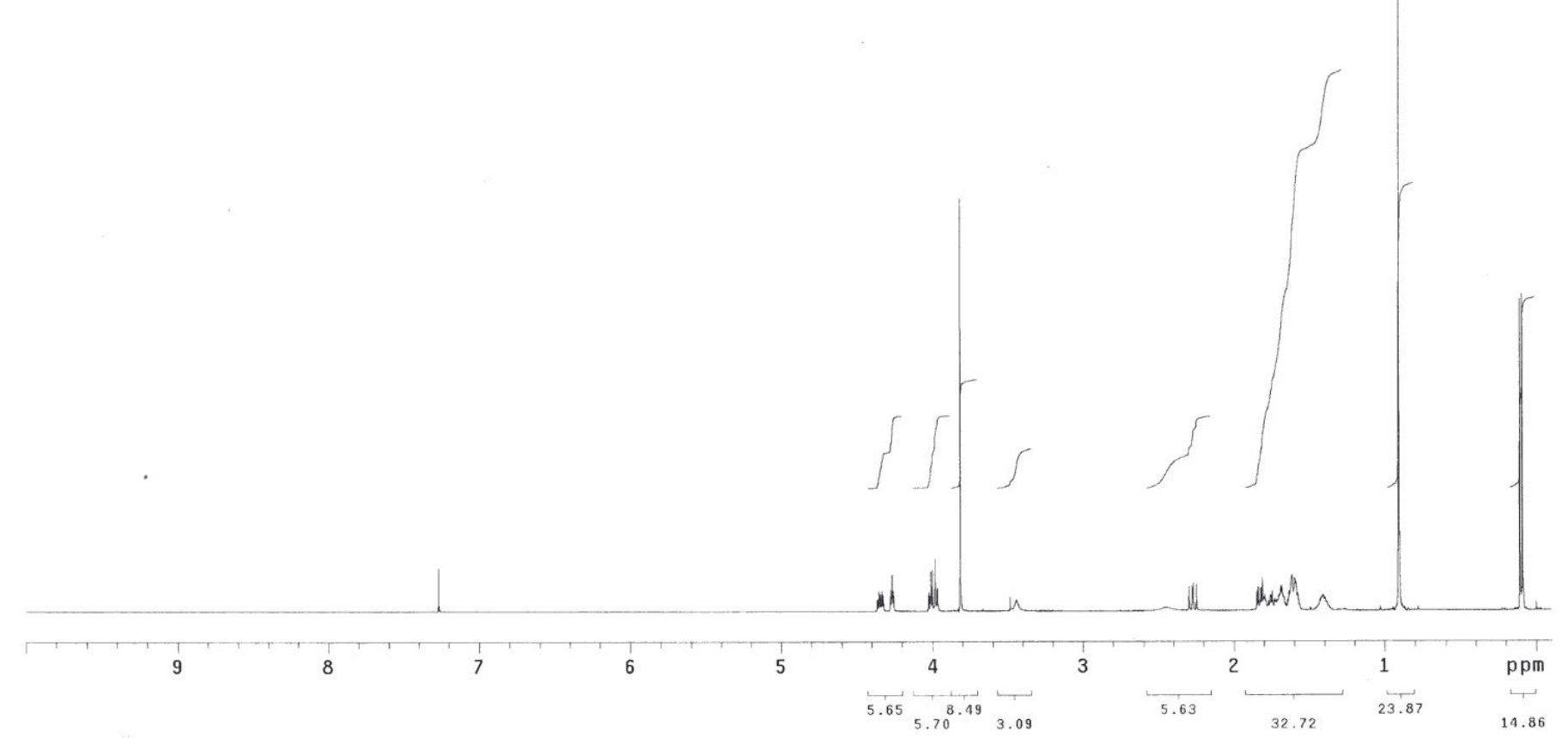

$500 \mathrm{MHz}$ 


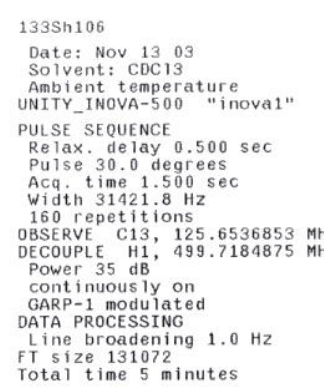

${ }^{13} \mathrm{C}-\mathrm{NMR}$ spectrum of $\mathbf{8}$ in $\mathrm{CDCl}_{3}$

HO

OT OTBDMS

W

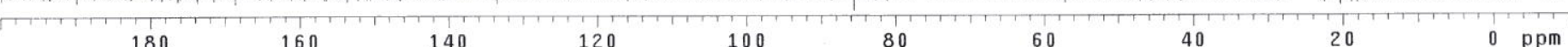

$125.6 \mathrm{MHz}$ 


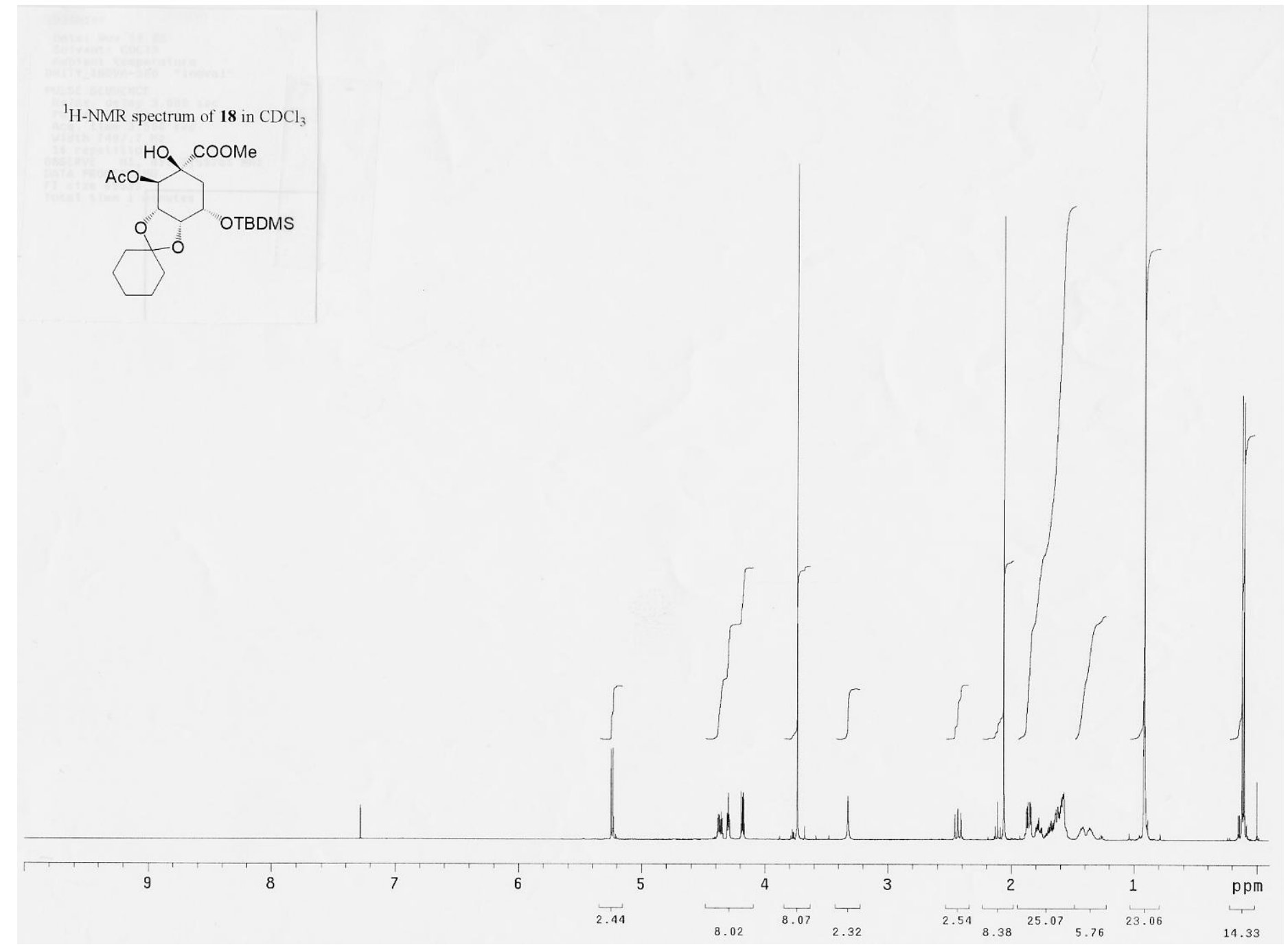

$500 \mathrm{HMz}$ 


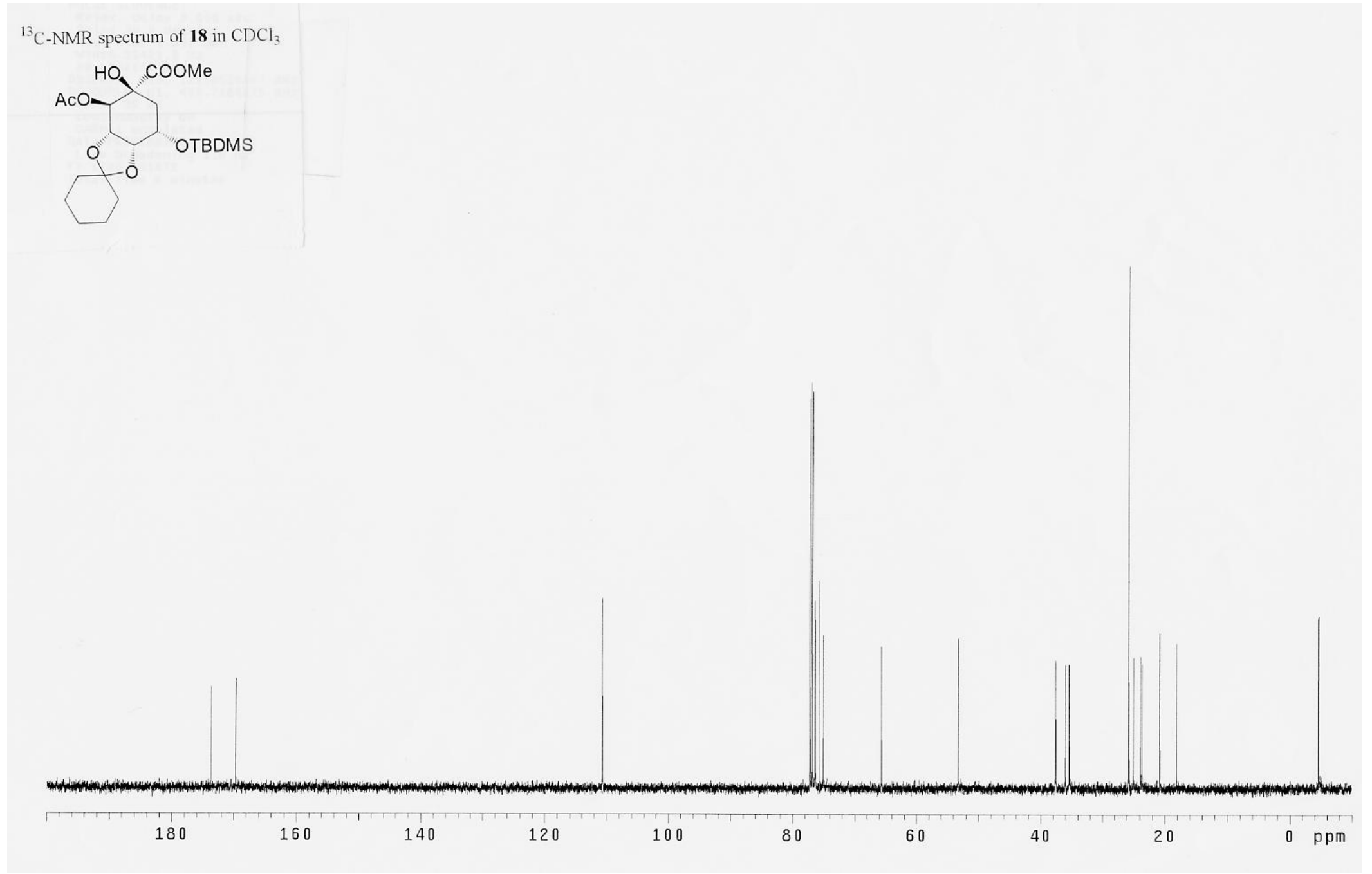

$125.6 \mathrm{MHz}$ 


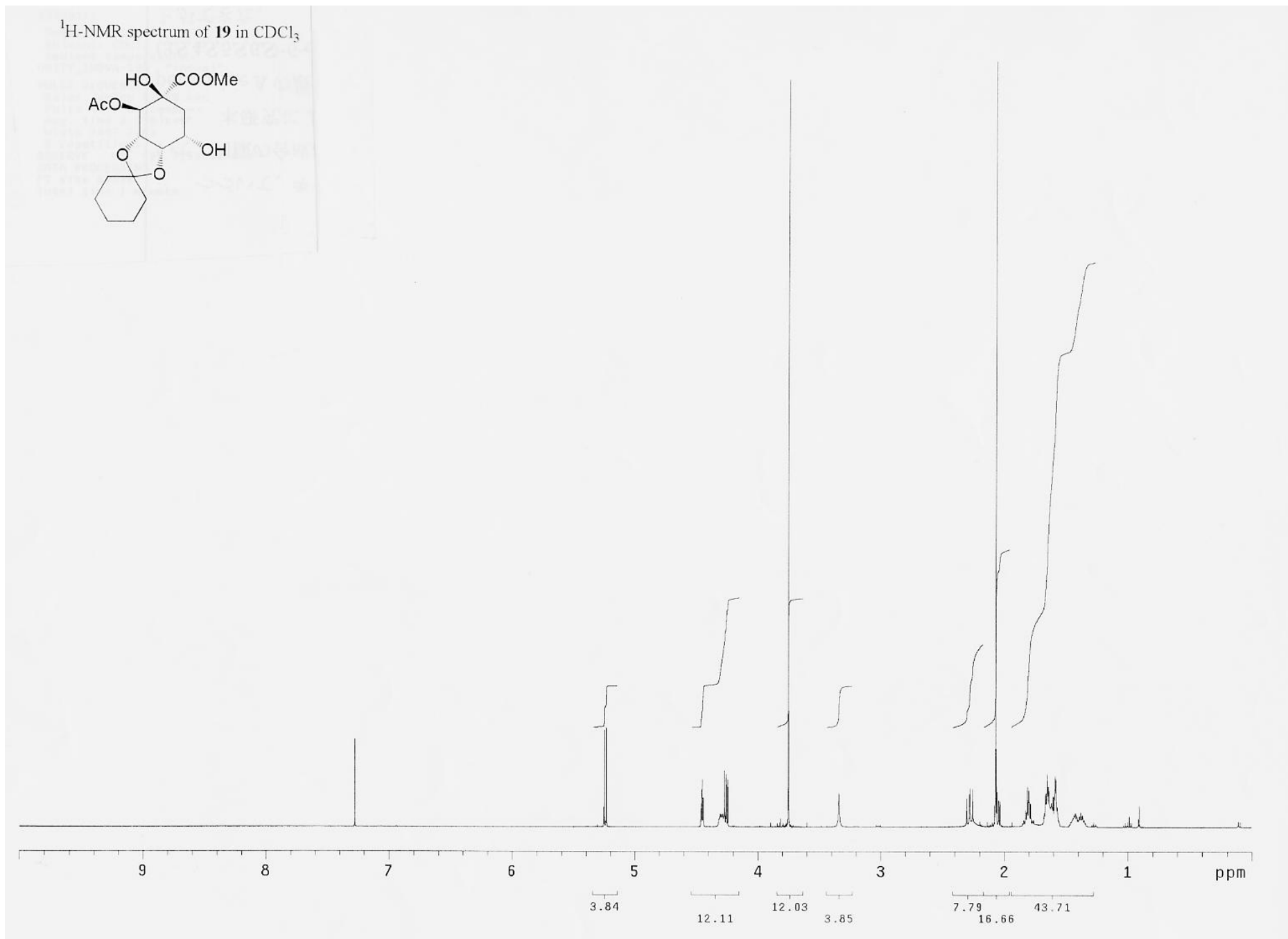

$500 \mathrm{MHz}$ 


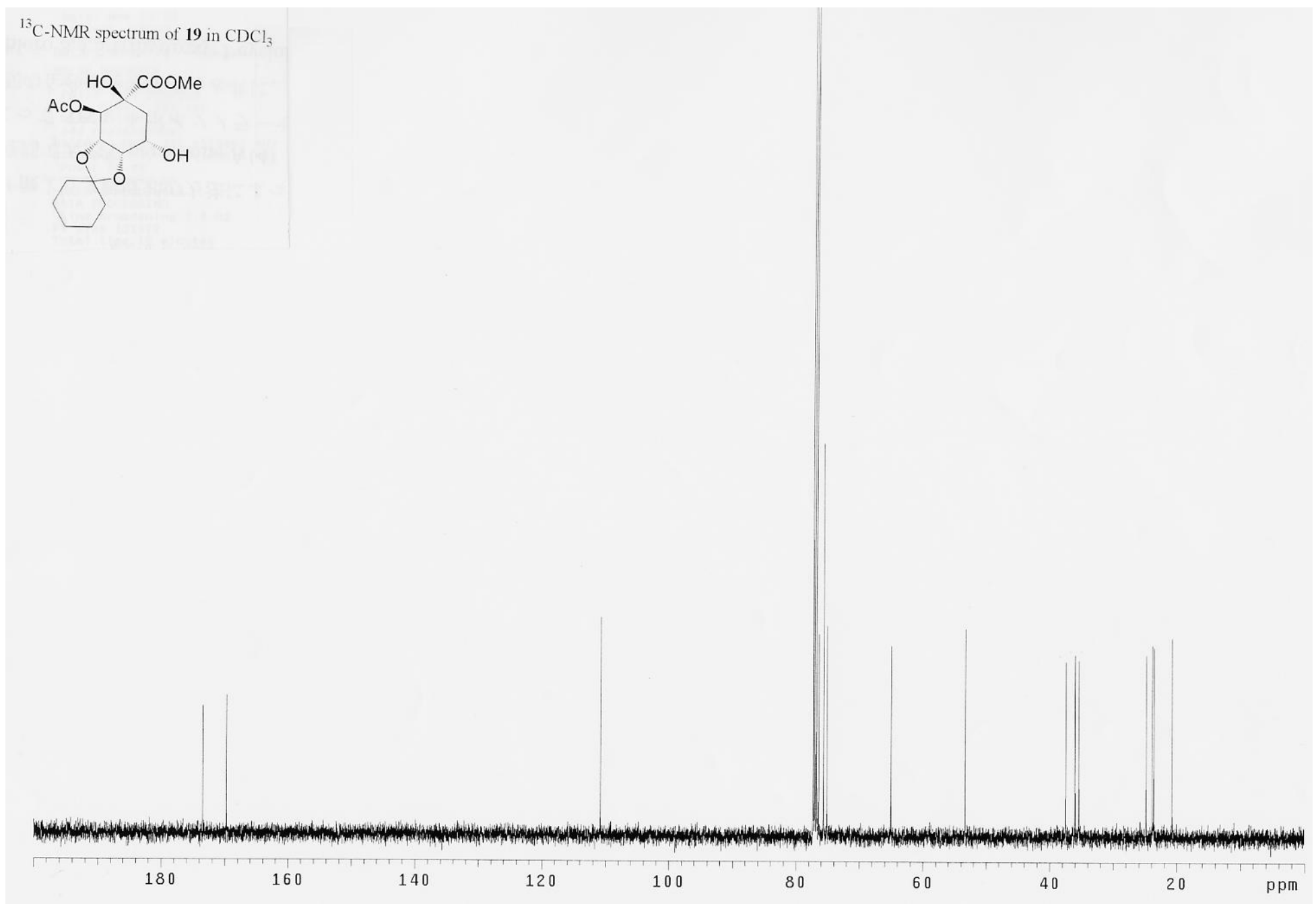

$125.6 \mathrm{MHz}$ 


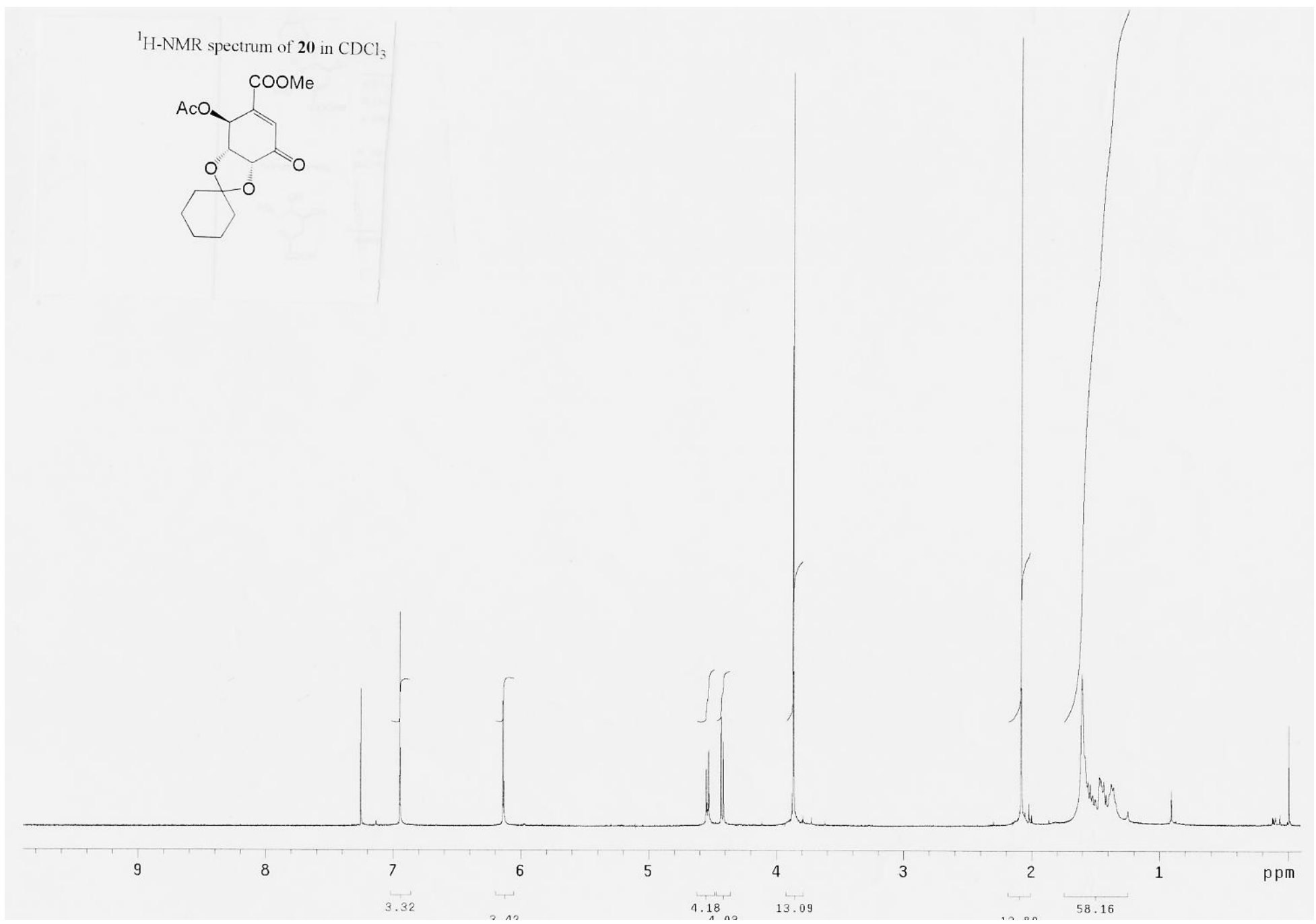

$300 \mathrm{MHz}$ 


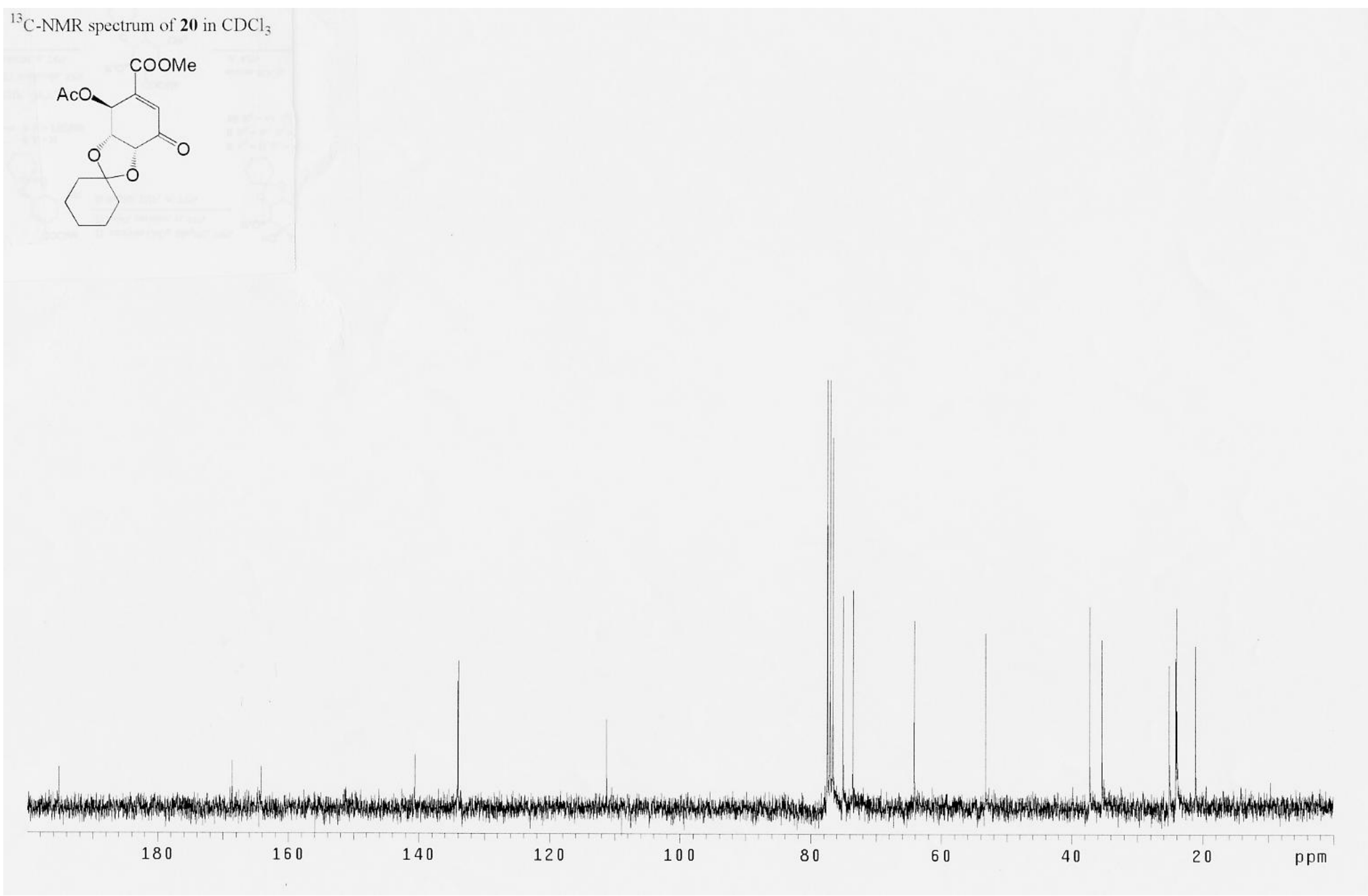

$75 \mathrm{MHz}$ 


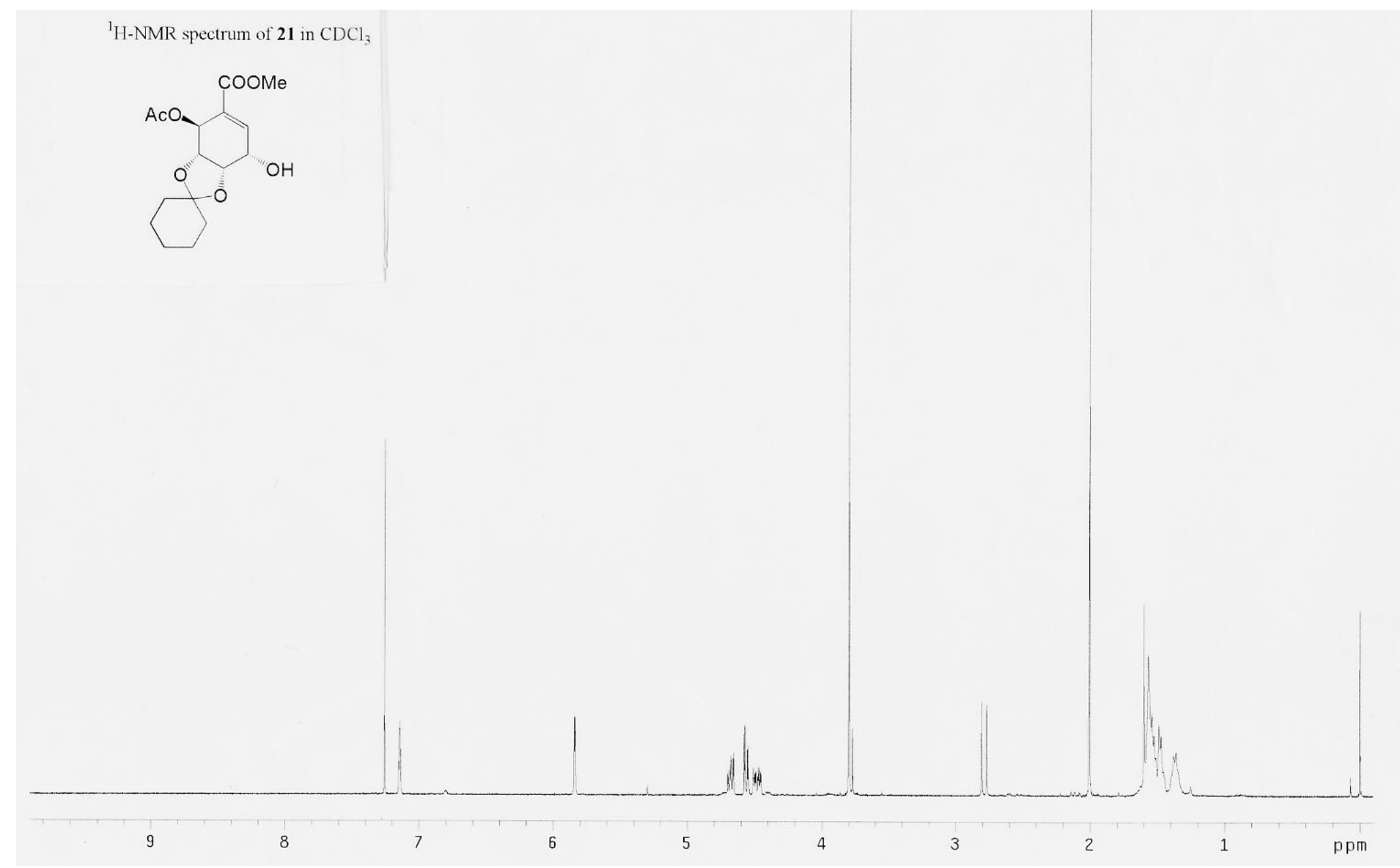

$300 \mathrm{MHz}$ 


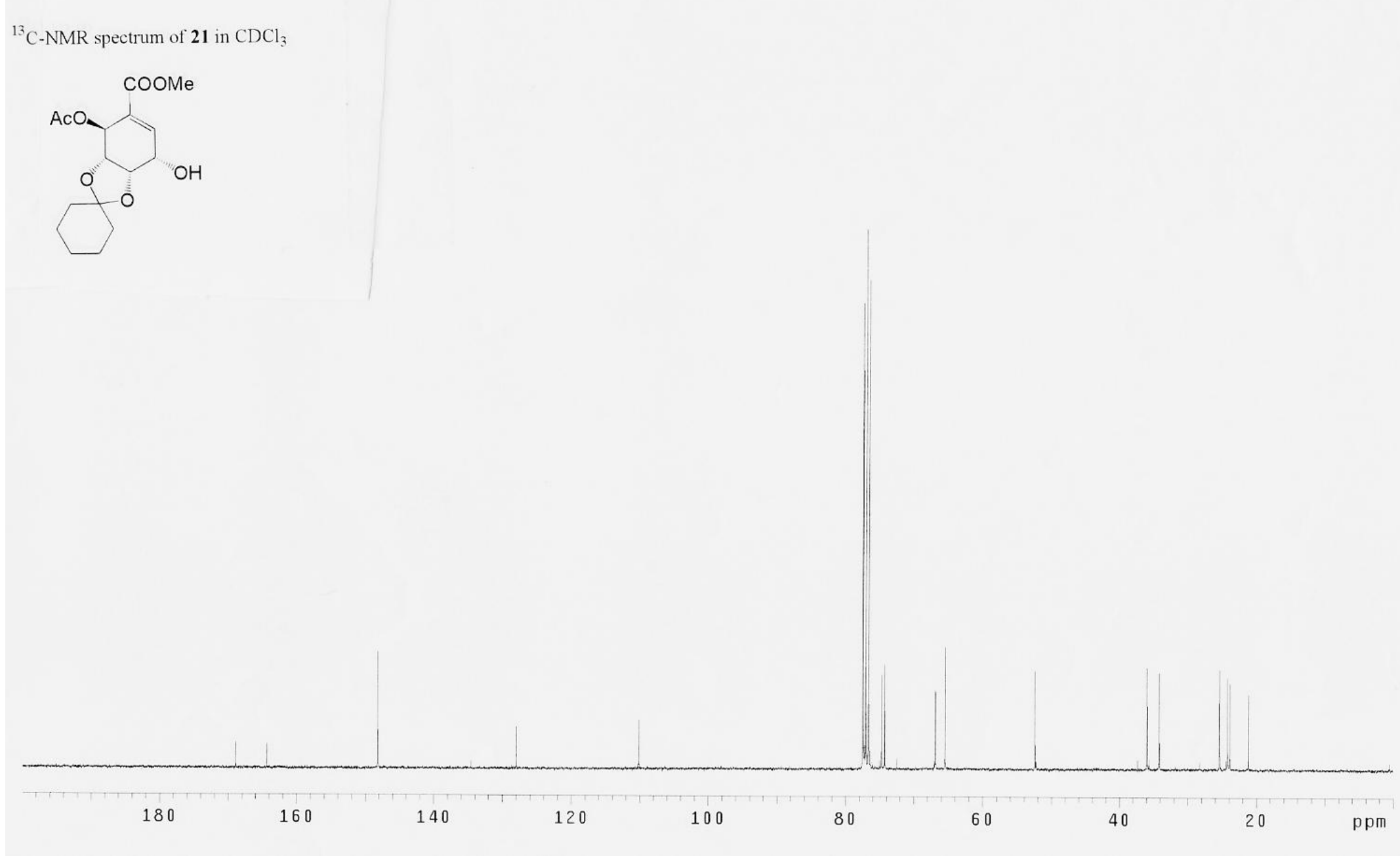

$75 \mathrm{MHz}$ 


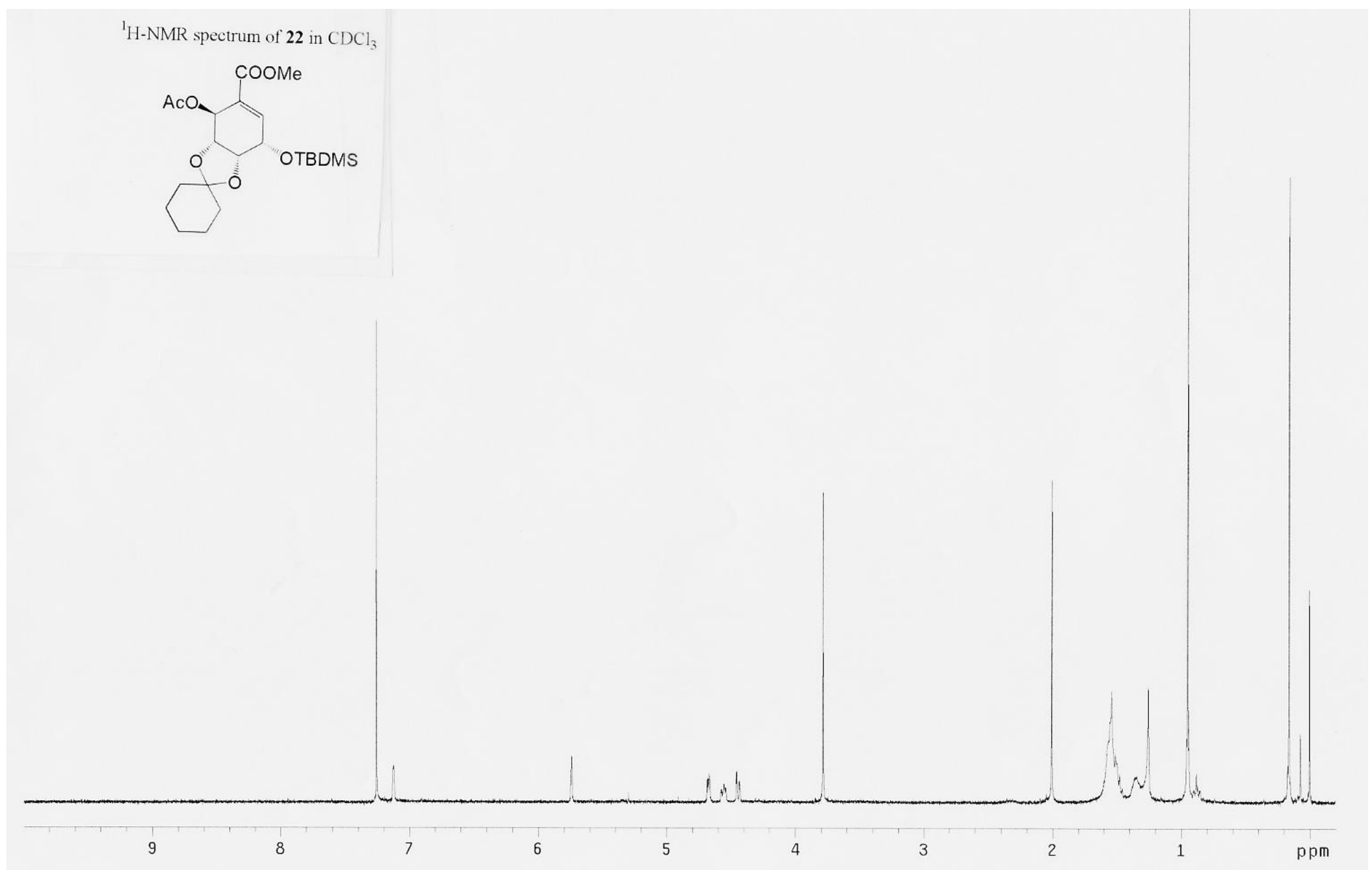

$300 \mathrm{MHz}$ 


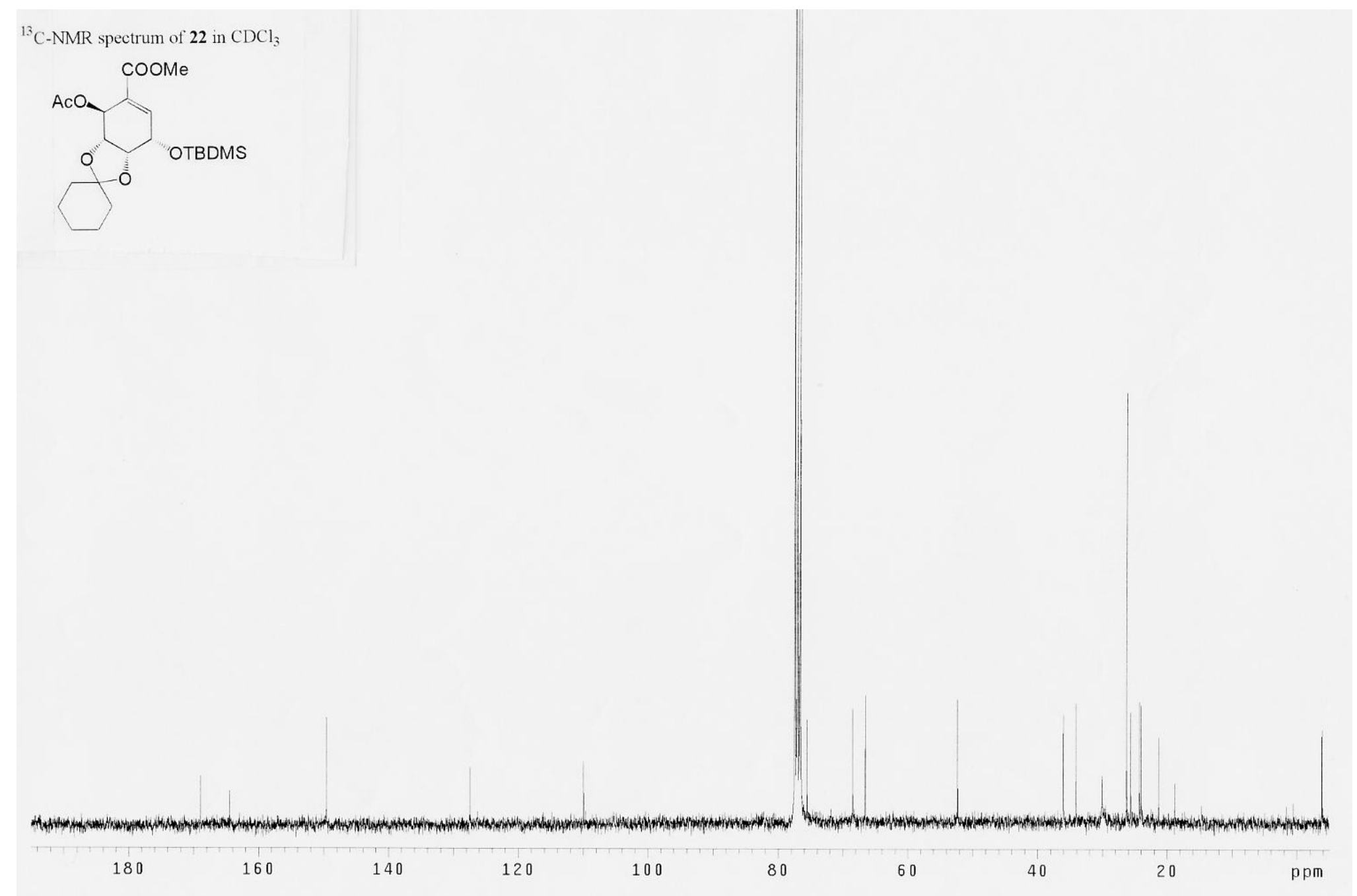

$75 \mathrm{MHz}$ 


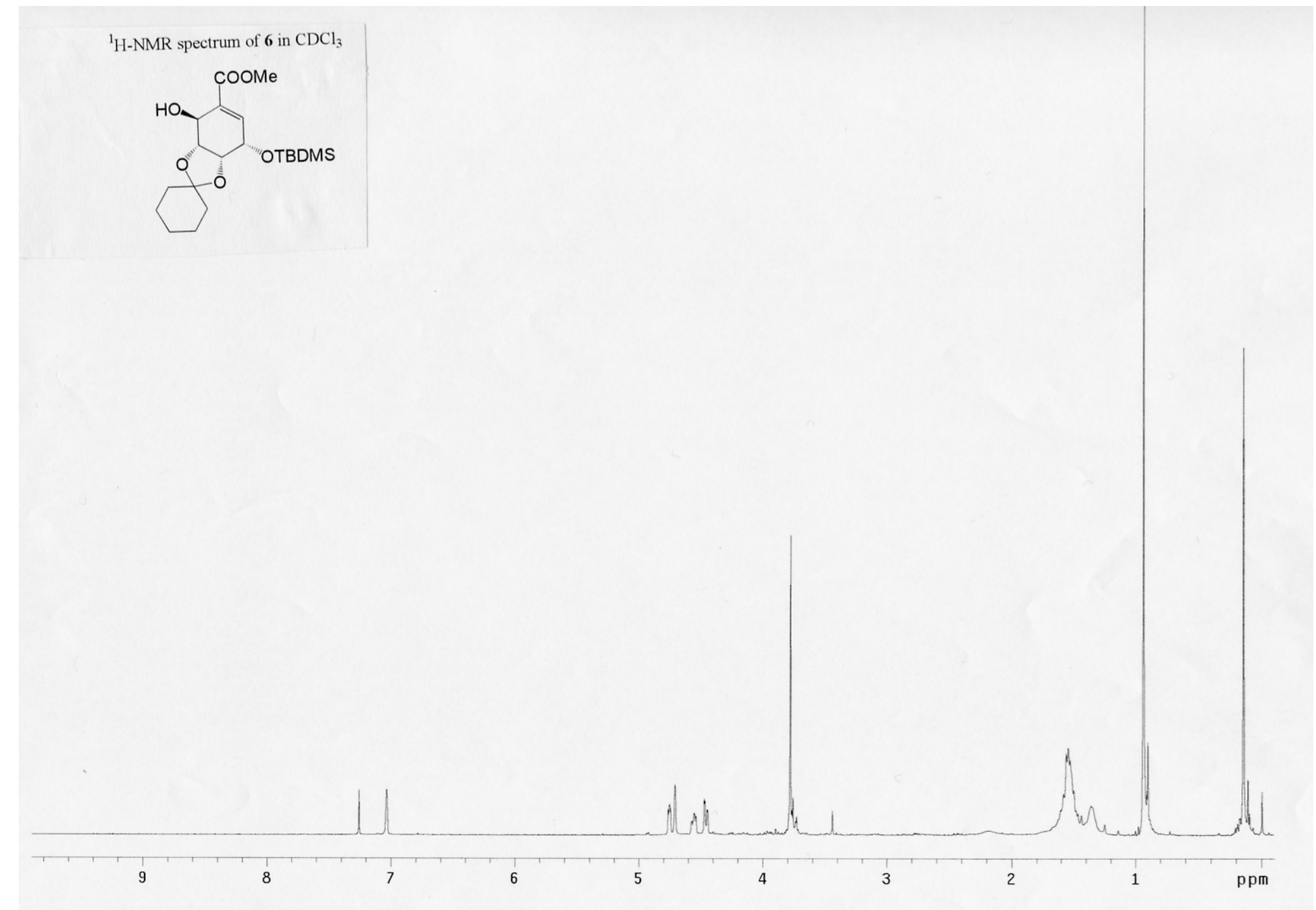

$300 \mathrm{MHz}$ 


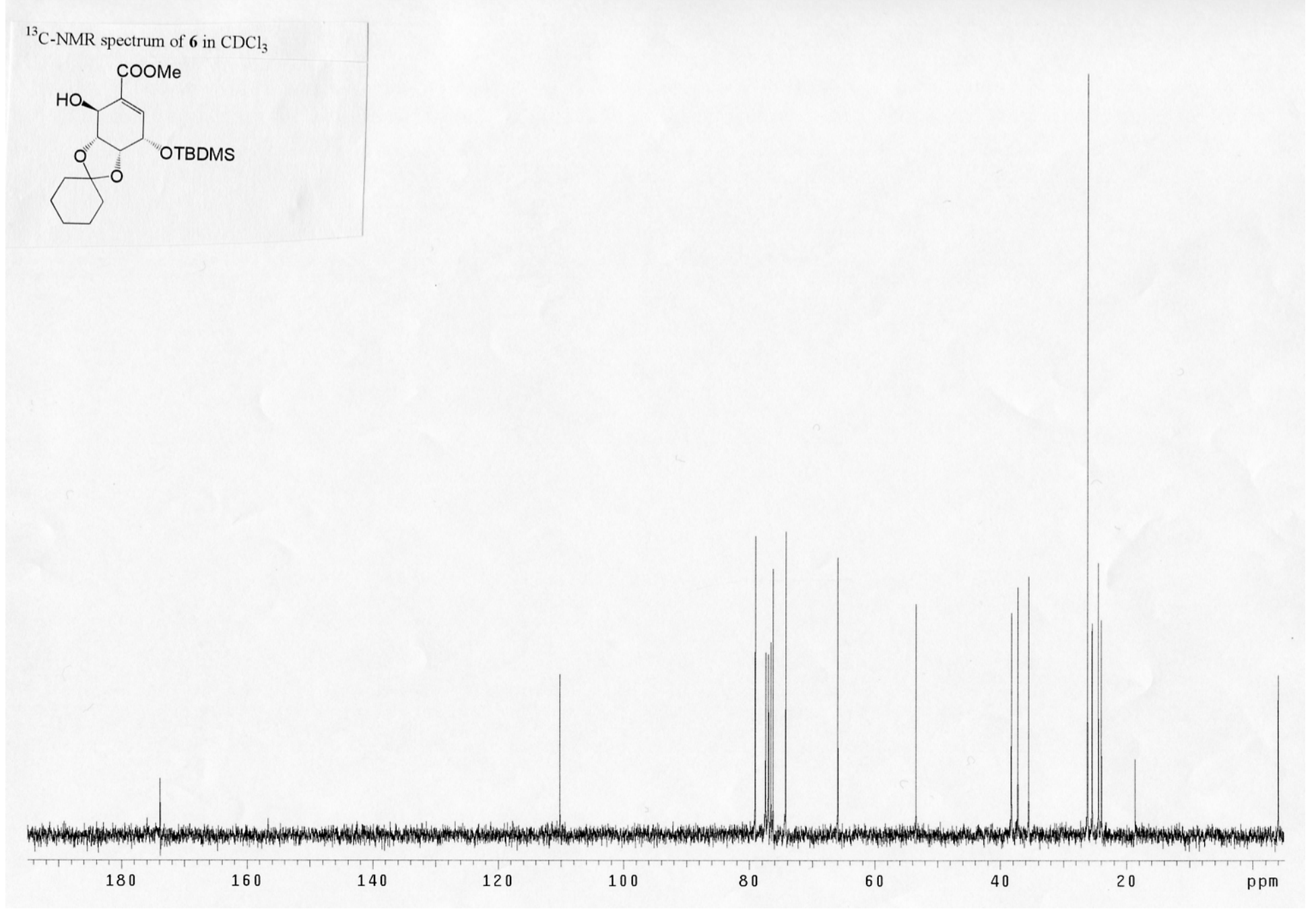

$75 \mathrm{MHz}$ 


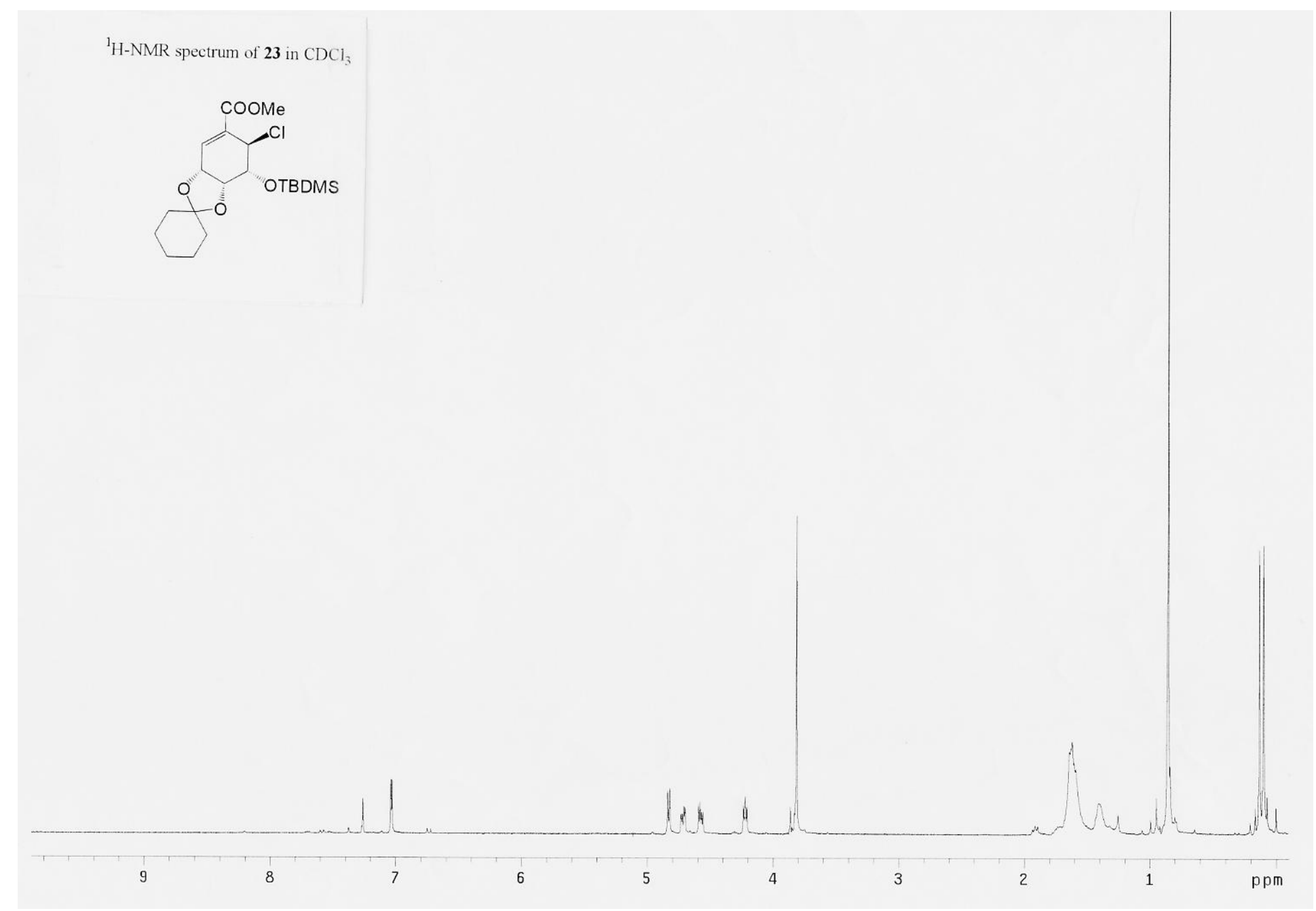

$300 \mathrm{MHz}$ 


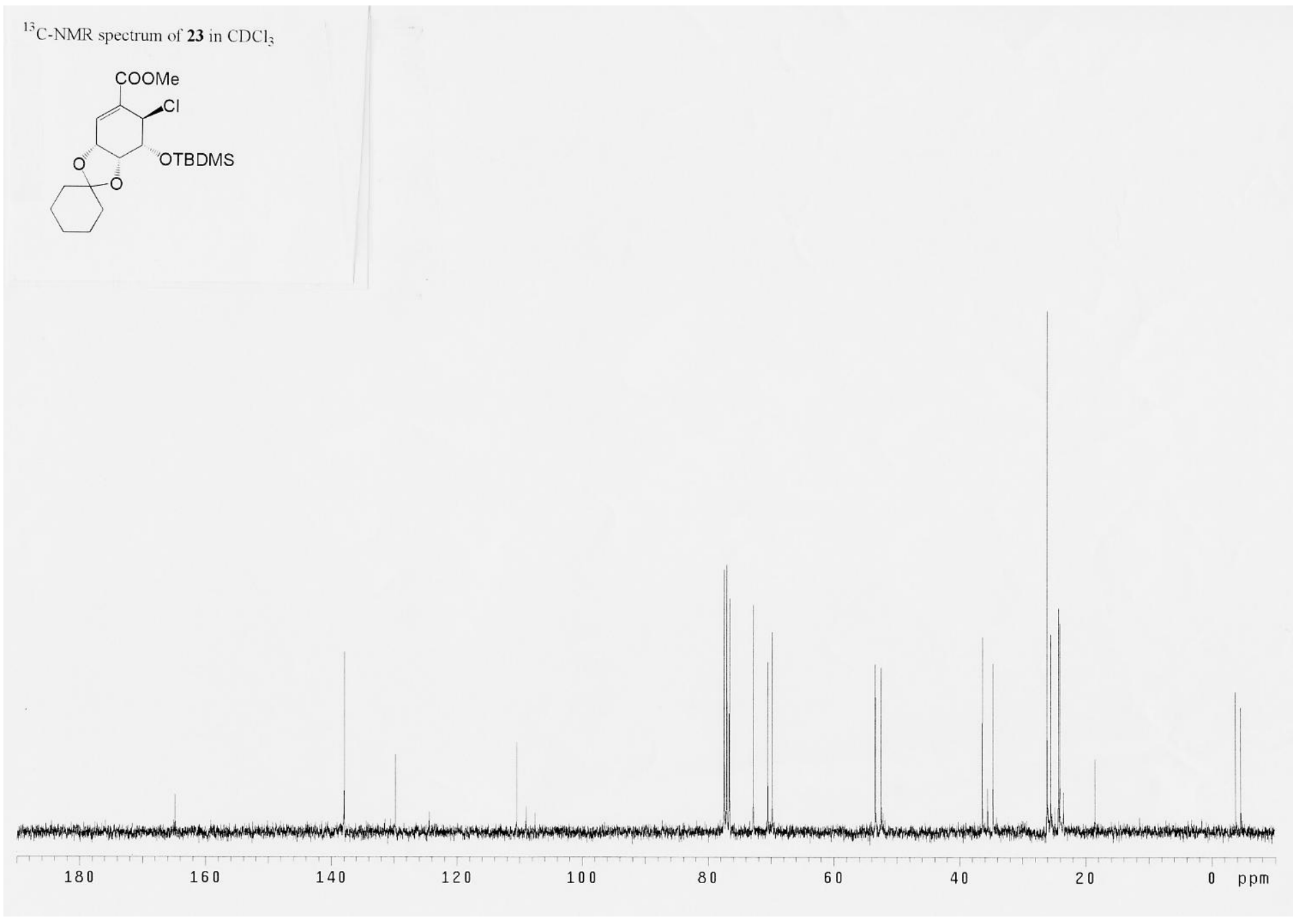

$75 \mathrm{MHz}$ 


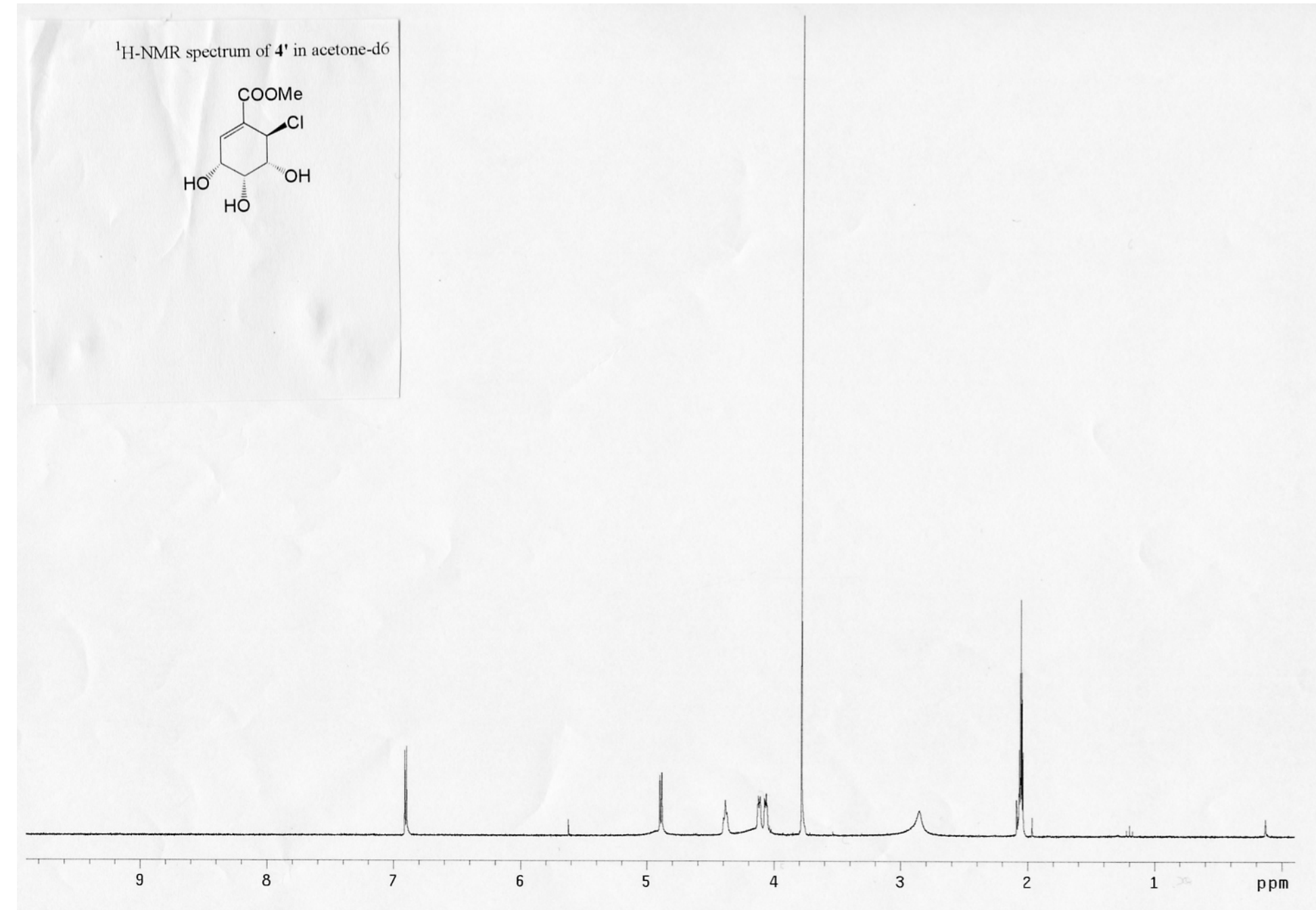

$300 \mathrm{MHz}$ 


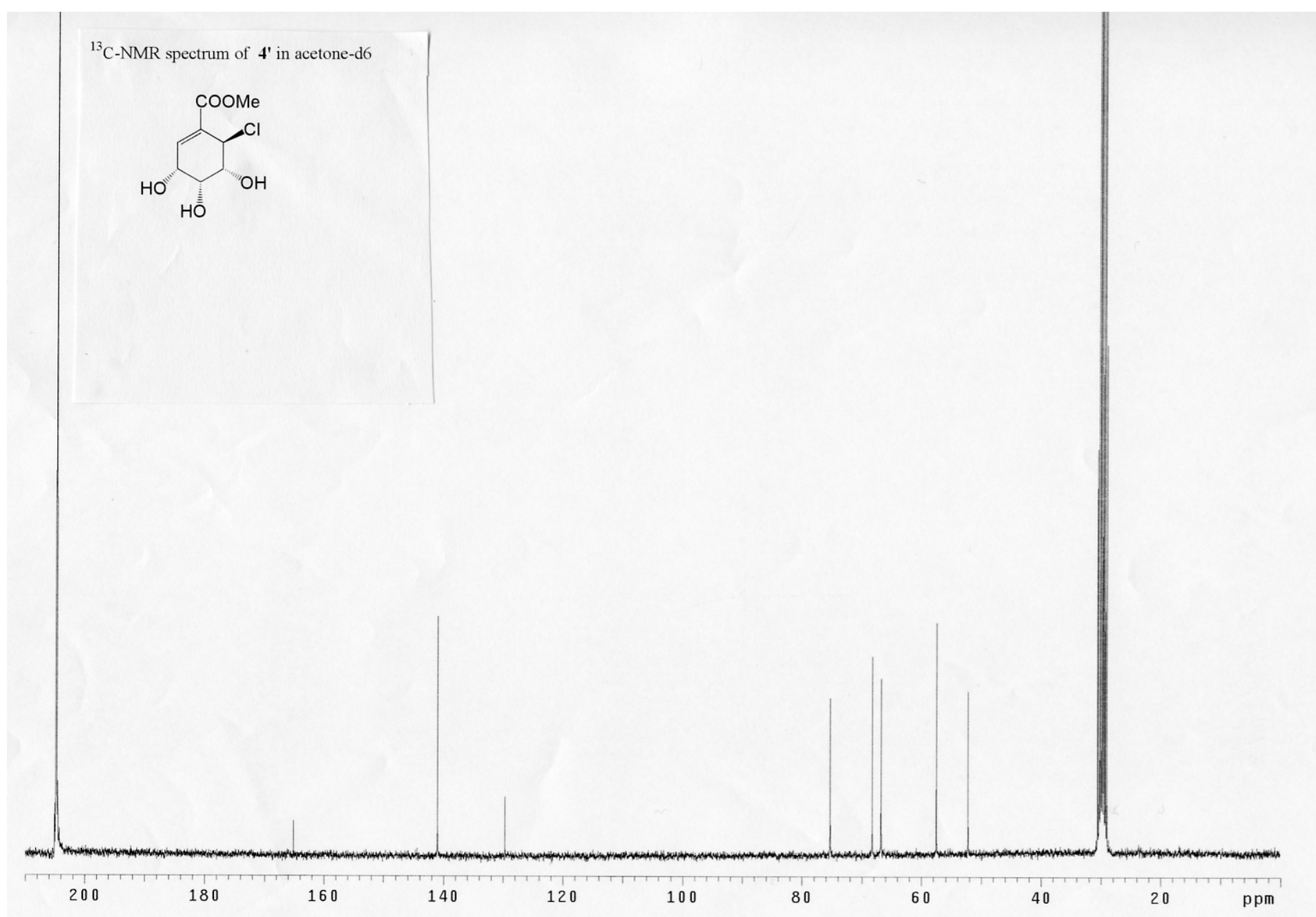

$75 \mathrm{MHz}$ 


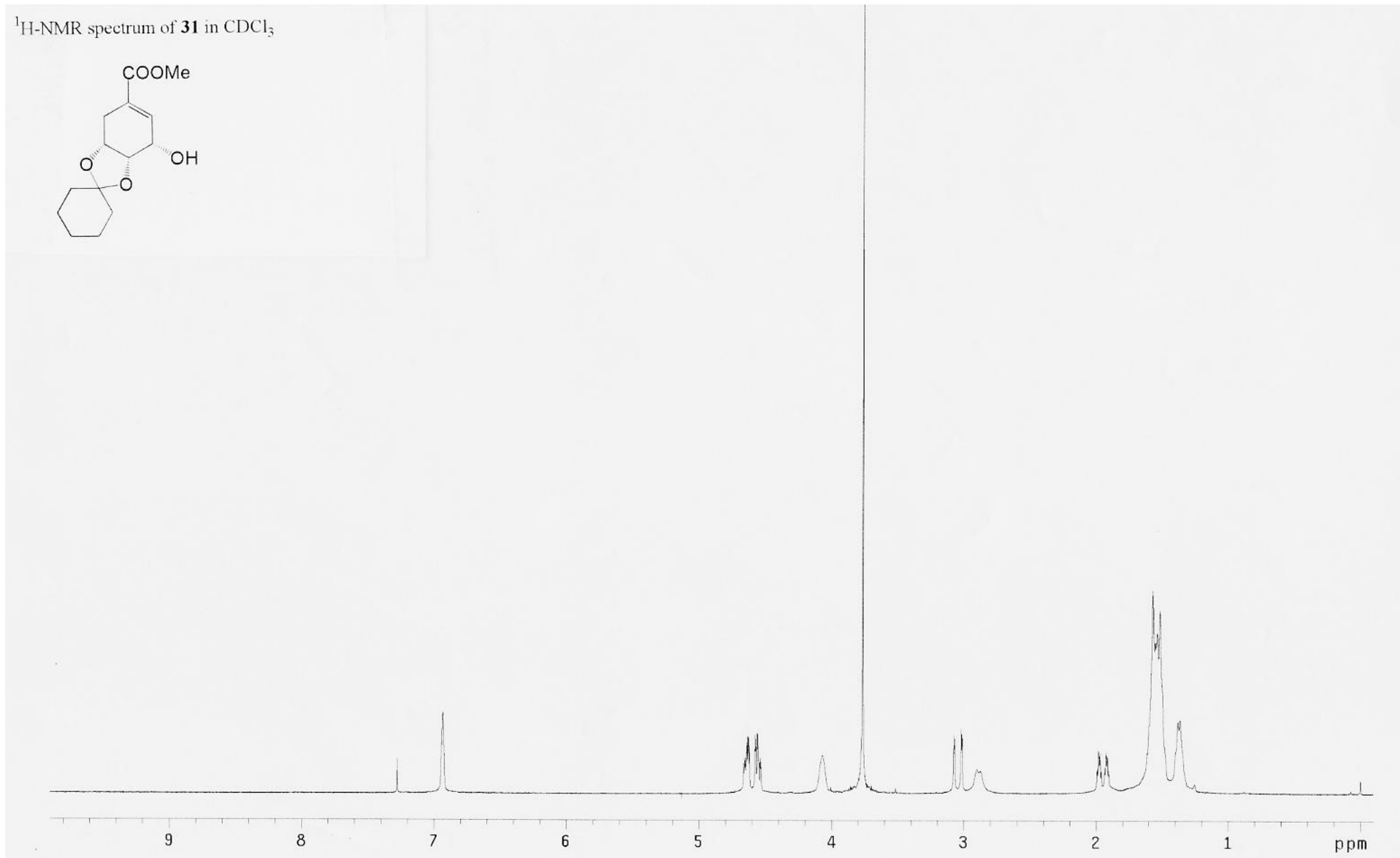

300MHz 


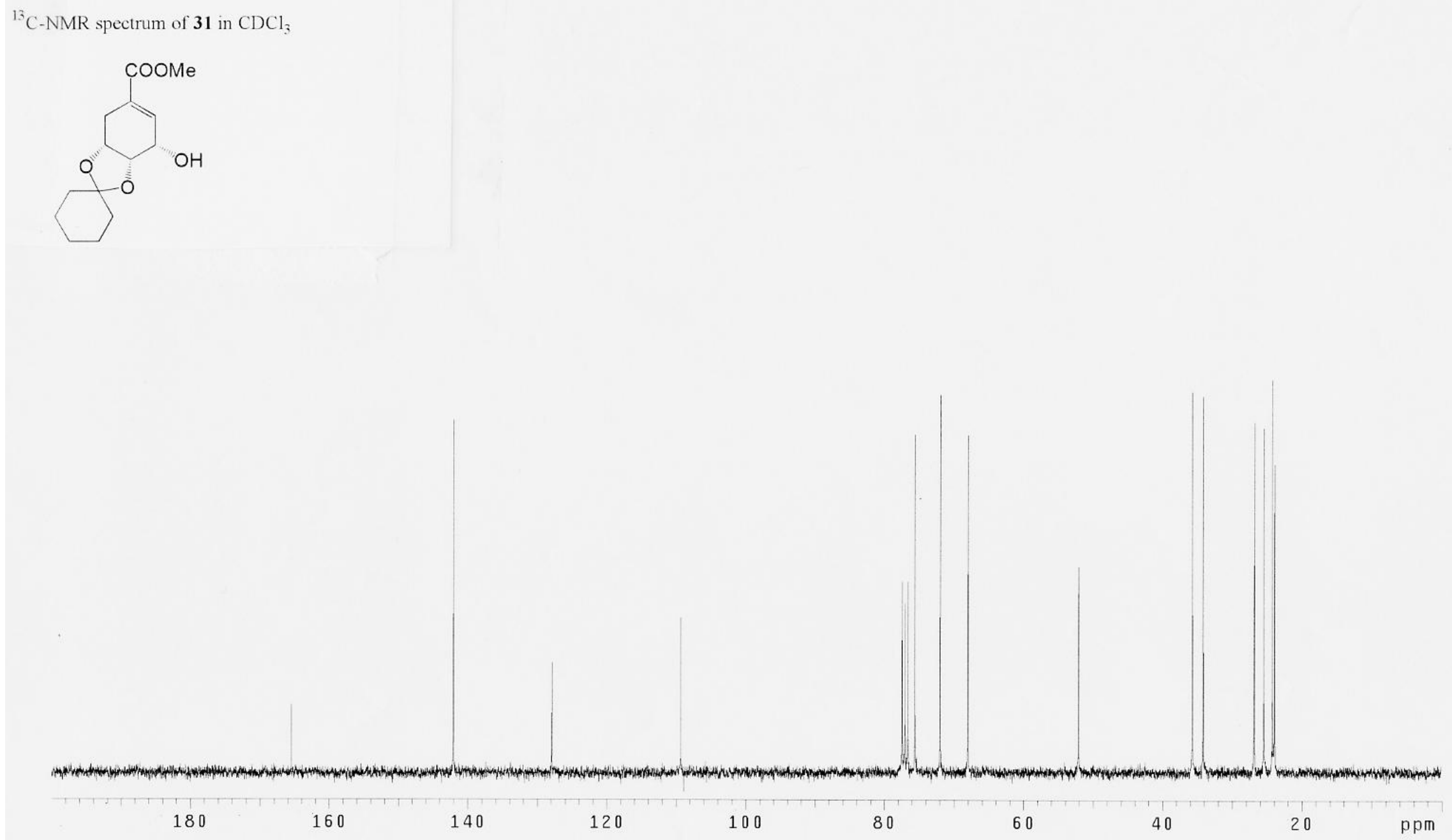

$75 \mathrm{MHz}$ 


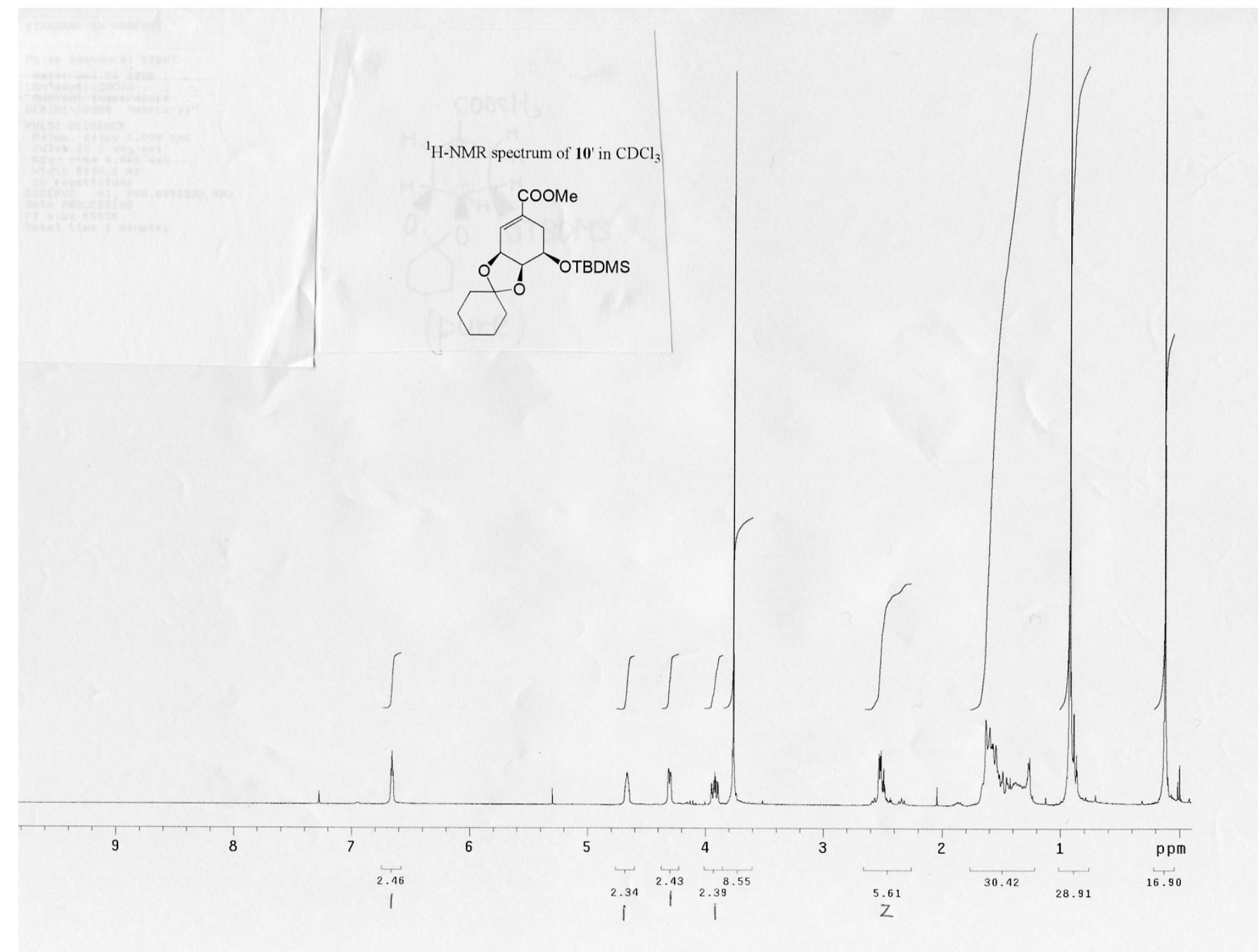

$300 \mathrm{MHz}$ 


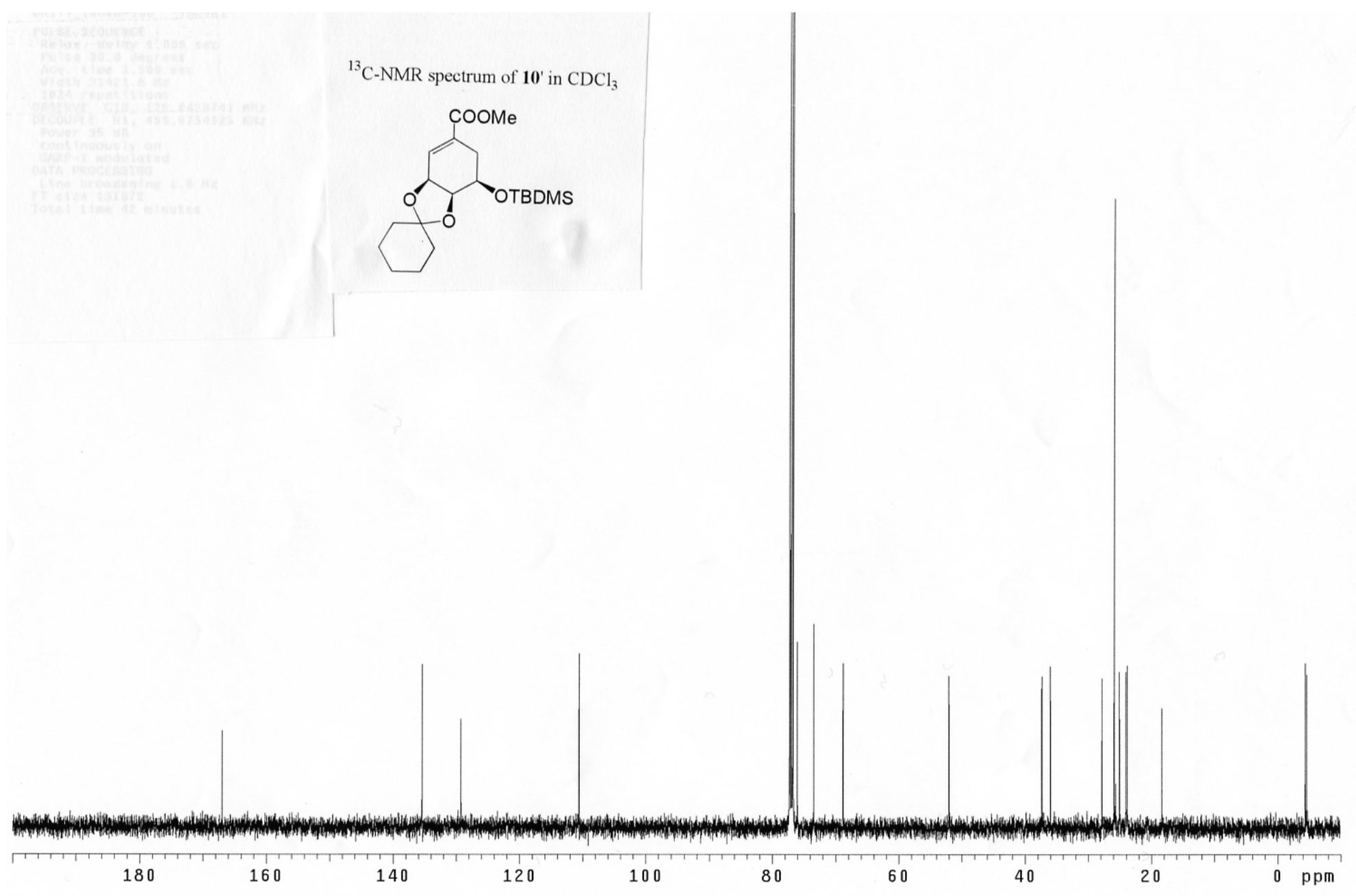

$75 \mathrm{MHz}$ 


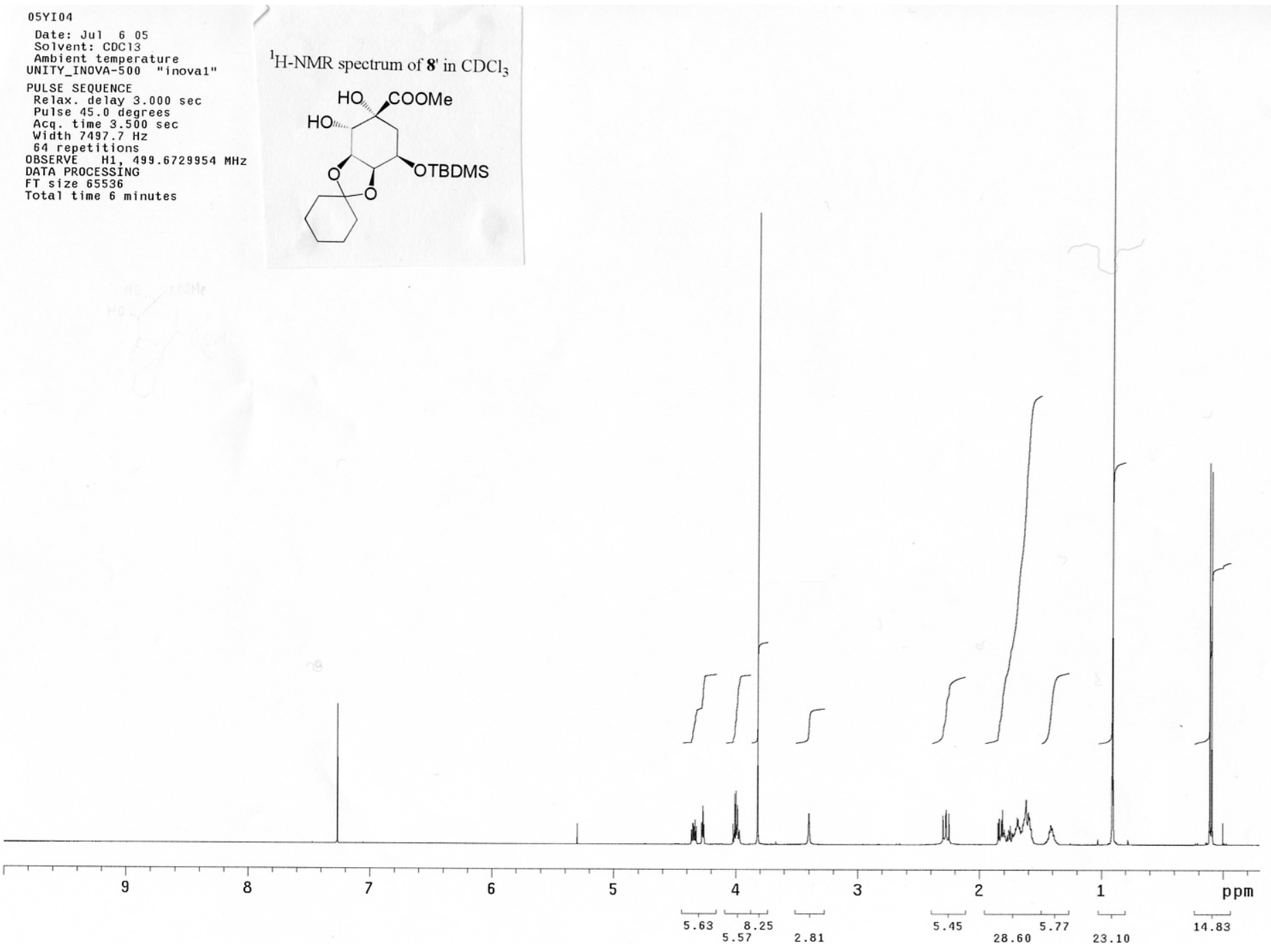

$500 \mathrm{MHz}$ 


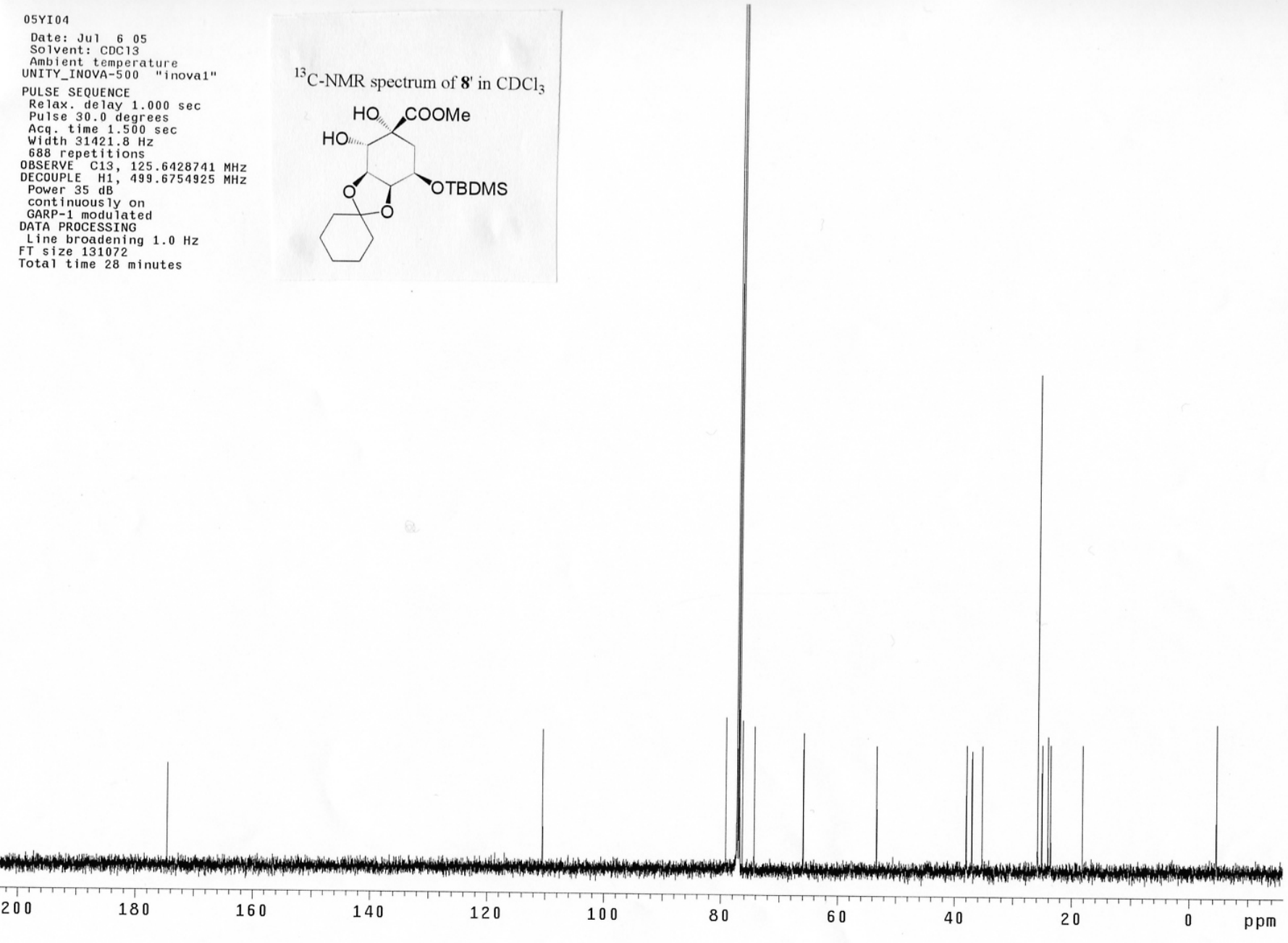

$125.6 \mathrm{MHz}$ 


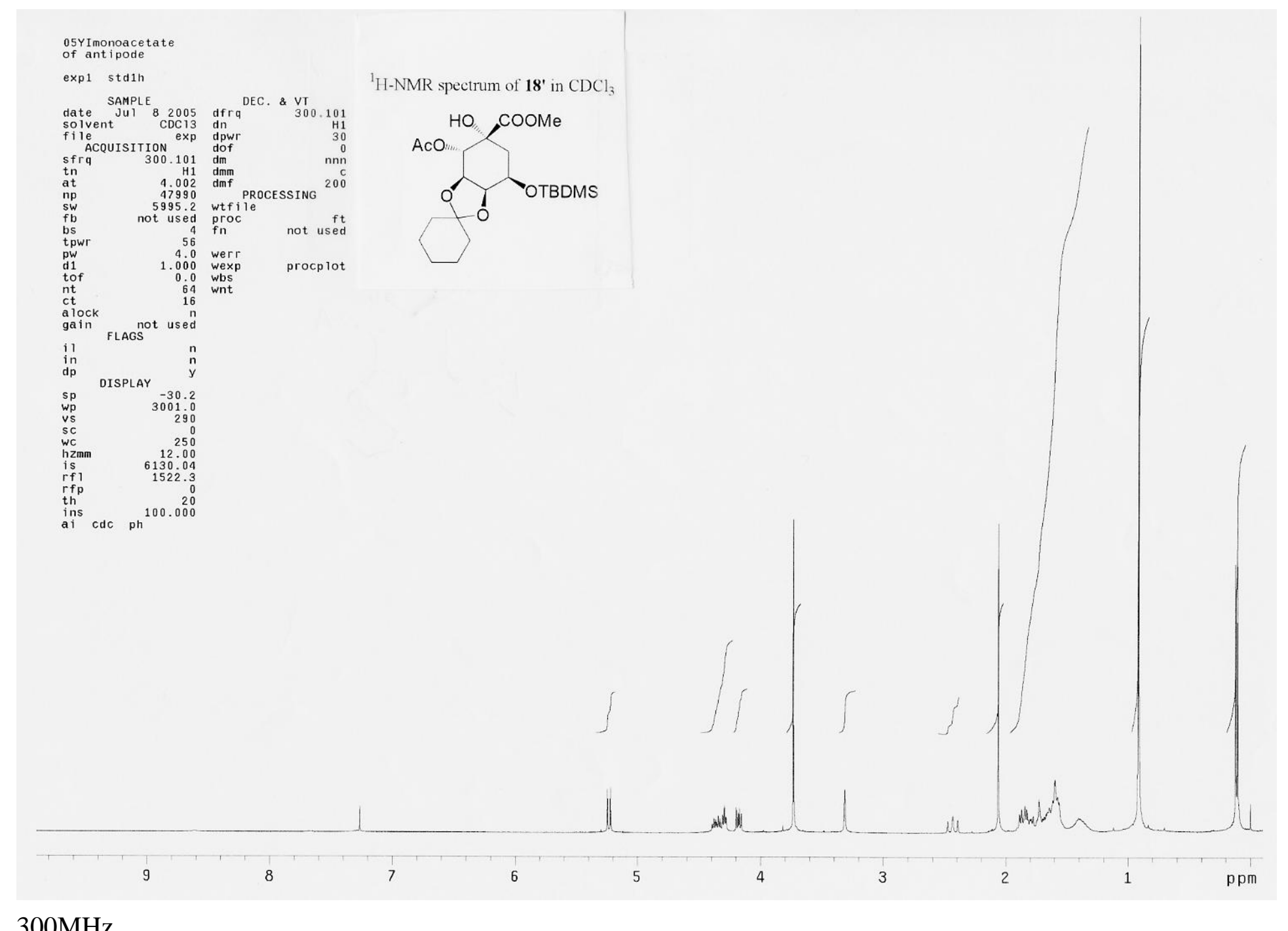




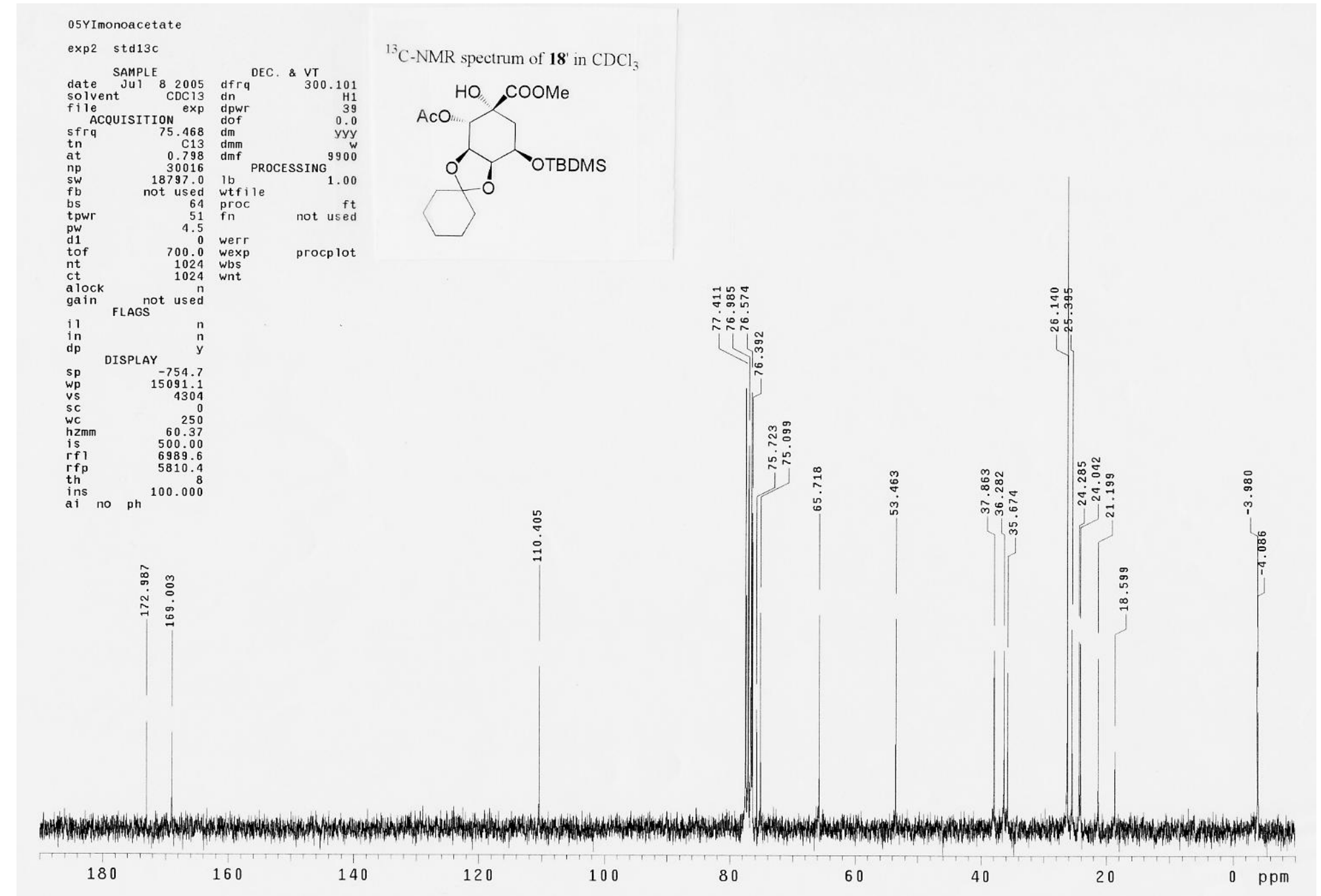

$75 \mathrm{MHz}$ 


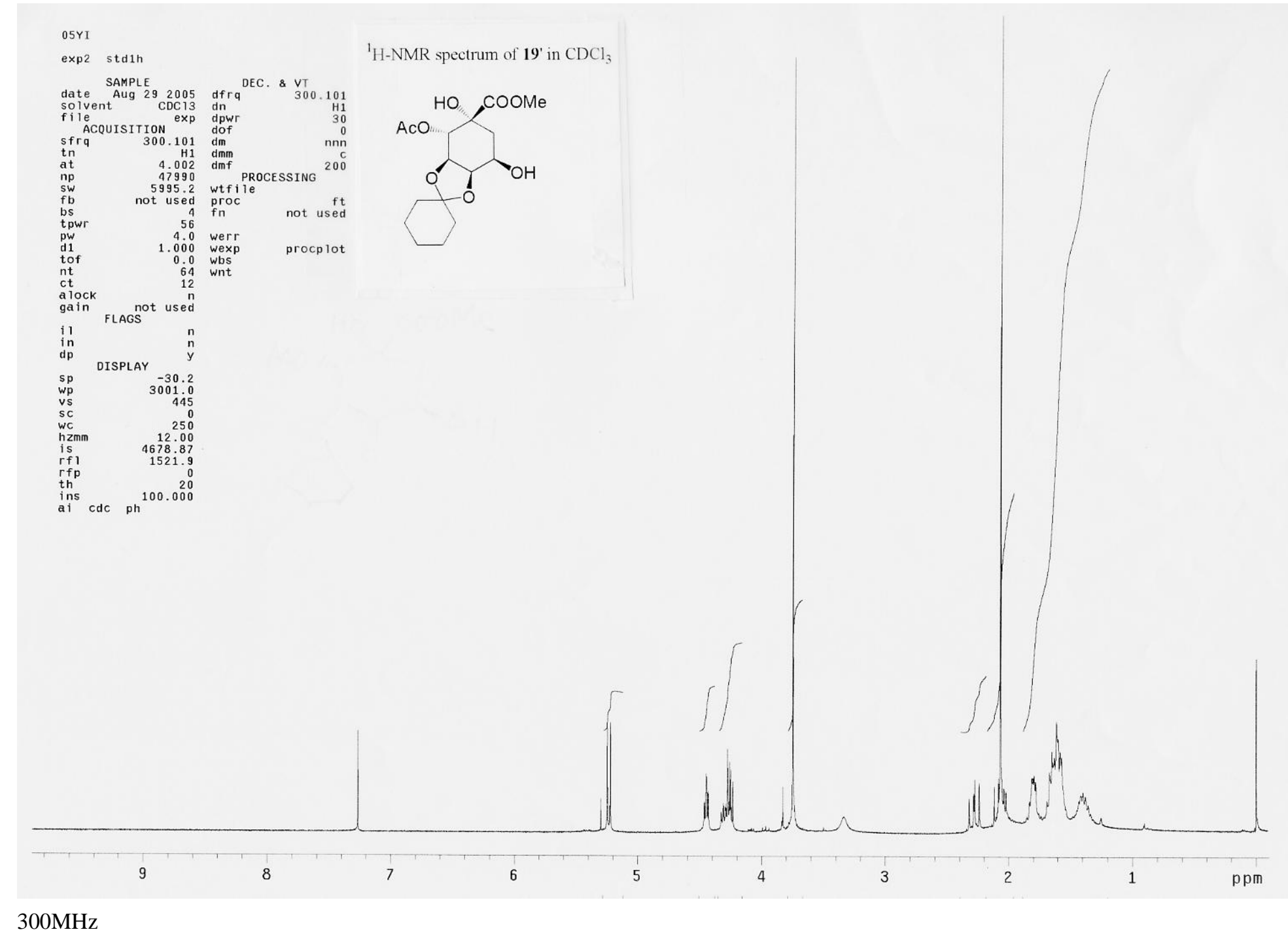




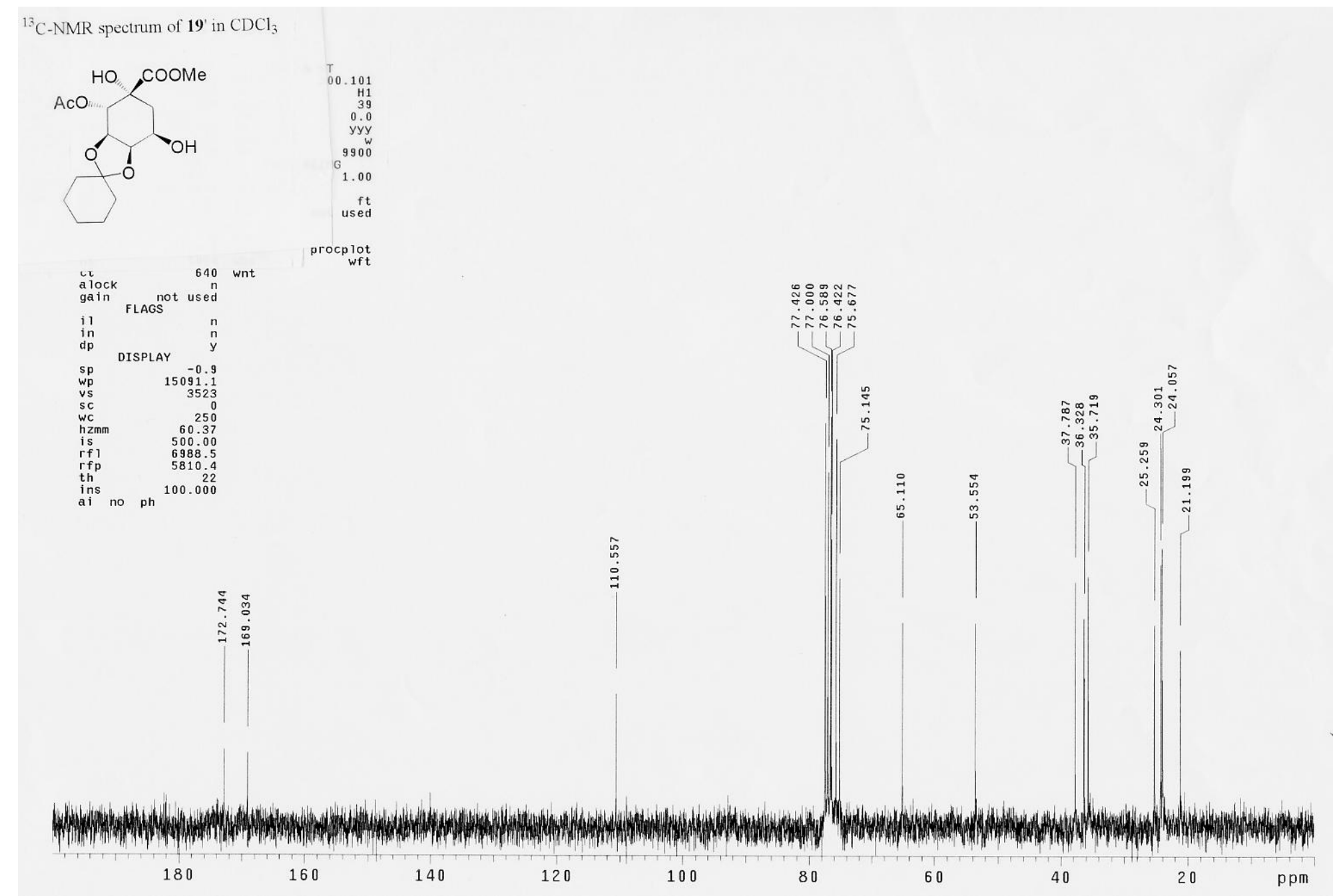

$75 \mathrm{MHz}$ 


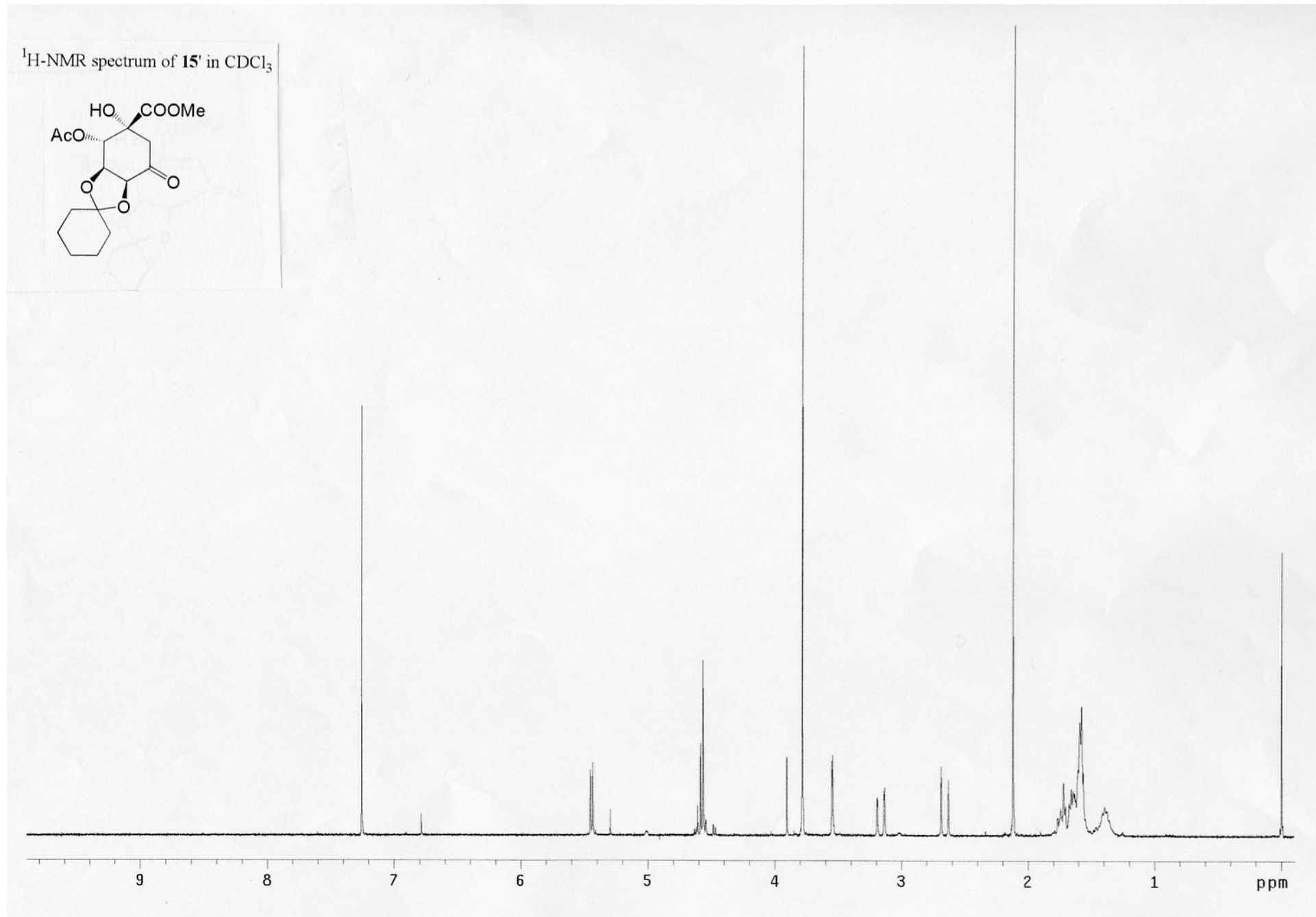

300MHz 


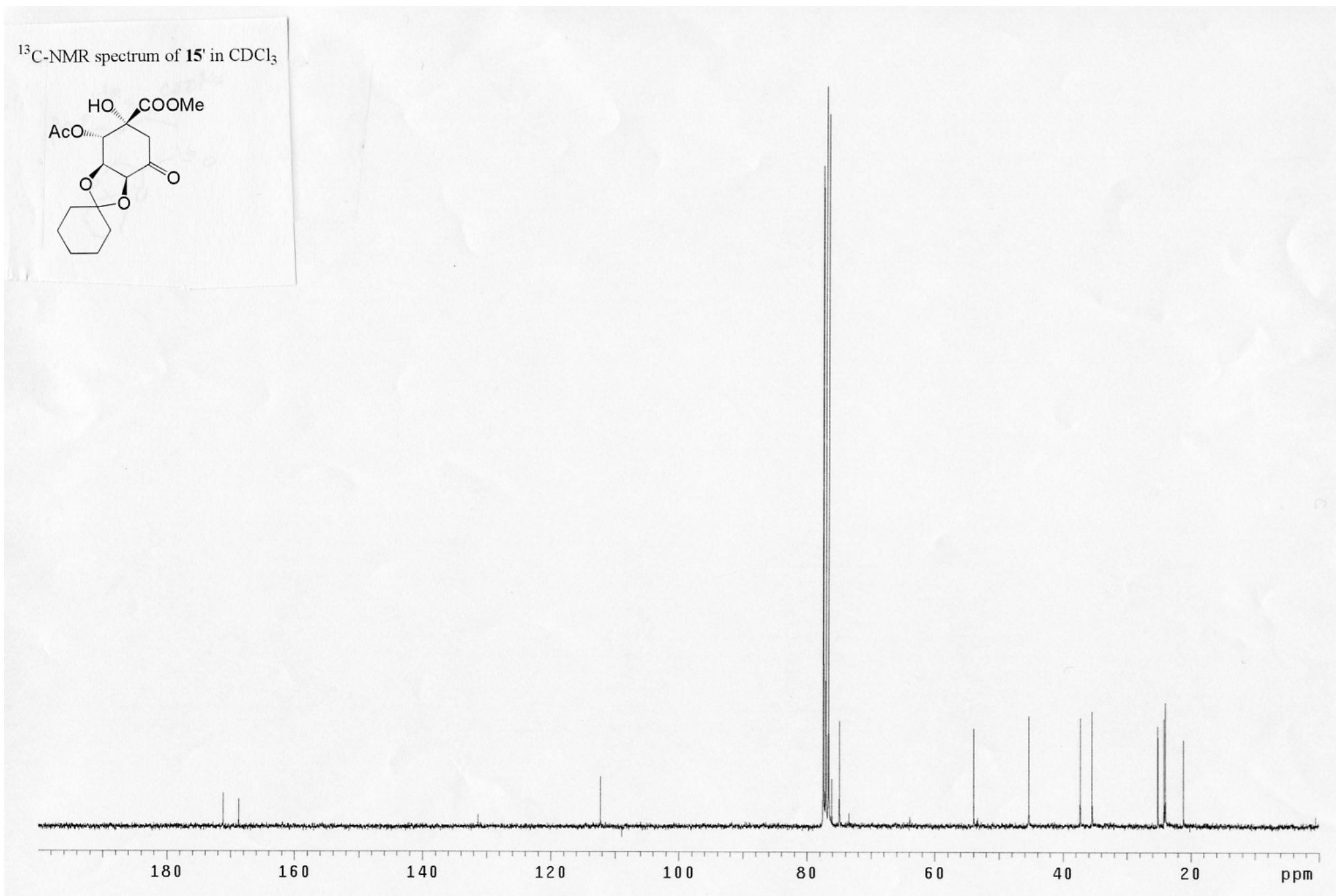

300MHz 
05Tuenone

Pulse Sequence: s2pu

Date: Aug 292005
Solvent: COC 13

Ambient temperature
GEMINI-300BB "mercury1"

PULSE SEQUENCE
Relax. delay $1.000 \mathrm{sec}$

Acq time $4.002 \mathrm{sec}$

16 repetitions

DATA PROCESSING
TT SIZE
T.

${ }^{1} \mathrm{H}-\mathrm{NMR}$ spectrum of $\mathbf{2 0}$ ' in $\mathrm{CDCl}_{3}$

COOMe

$\mathrm{AcO}$
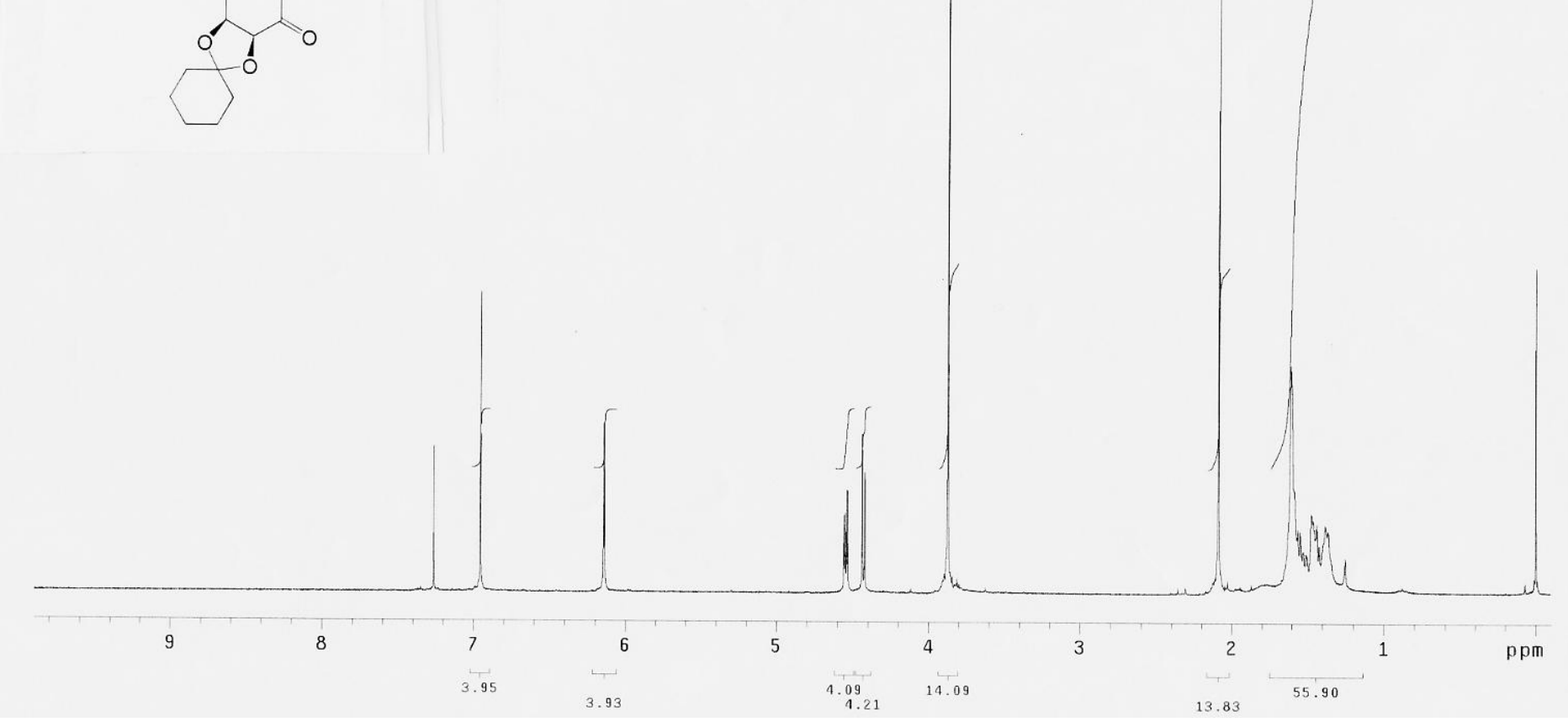

$300 \mathrm{MHz}$ 


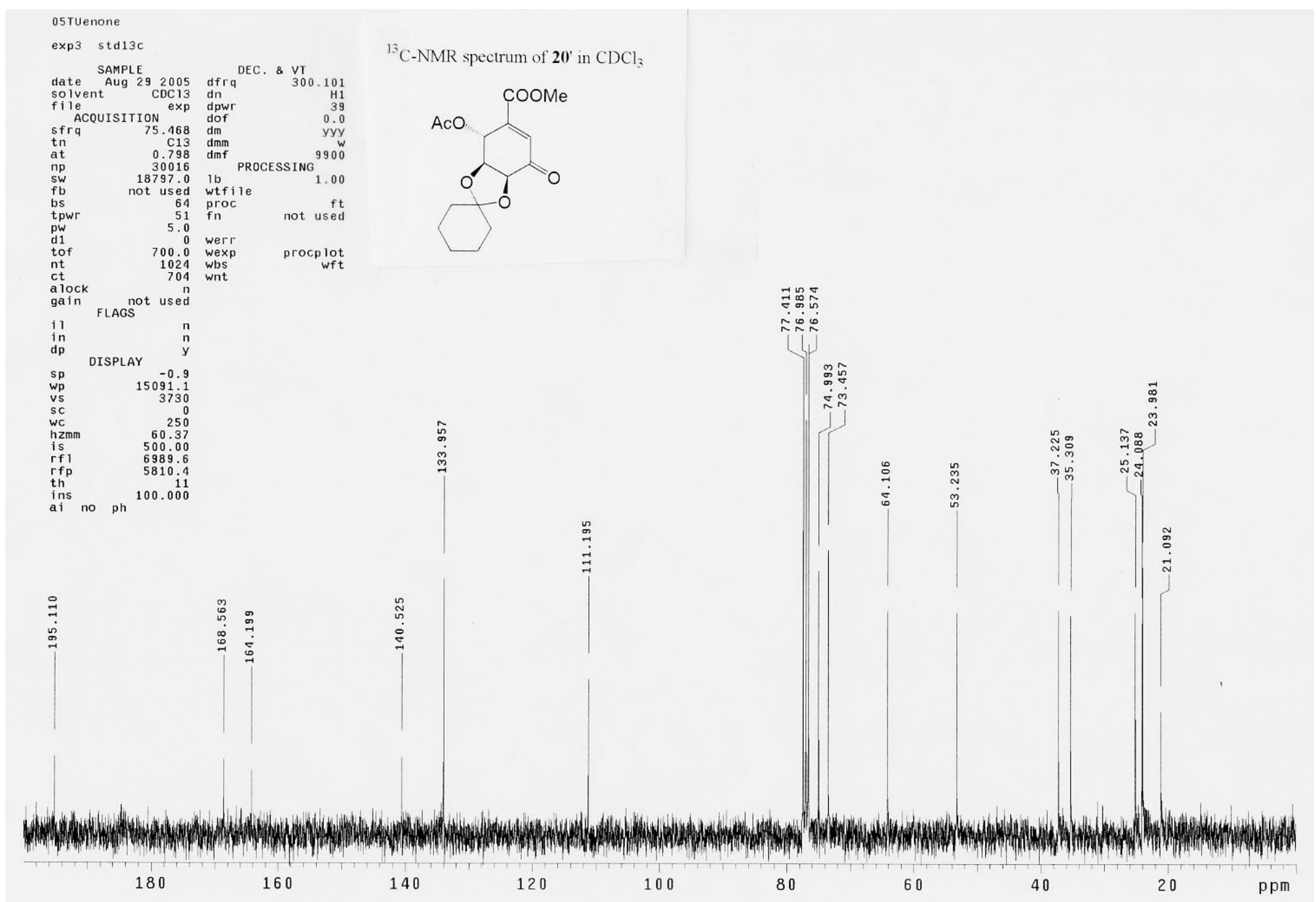

$75 \mathrm{MHz}$ 


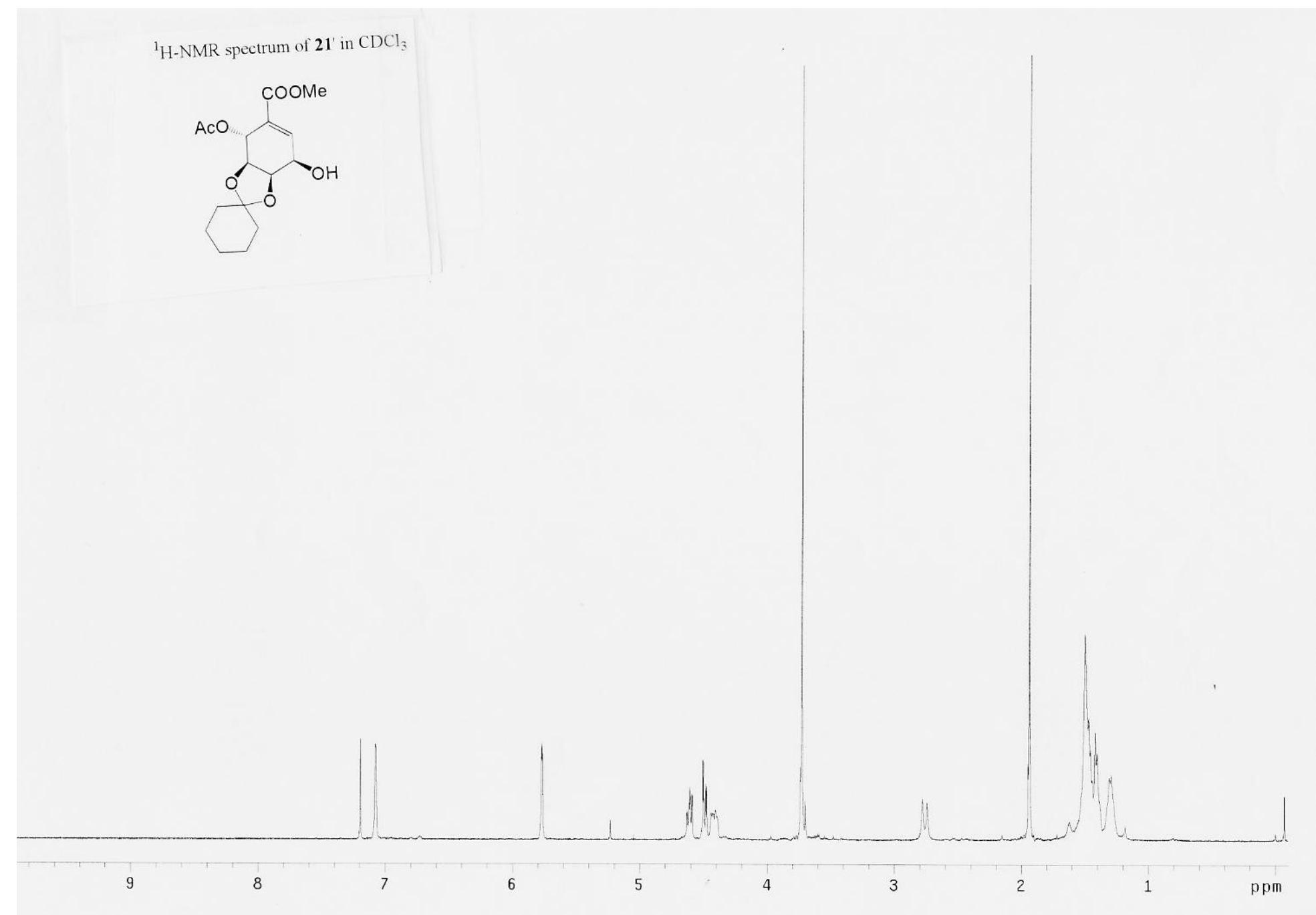

$300 \mathrm{MHz}$ 


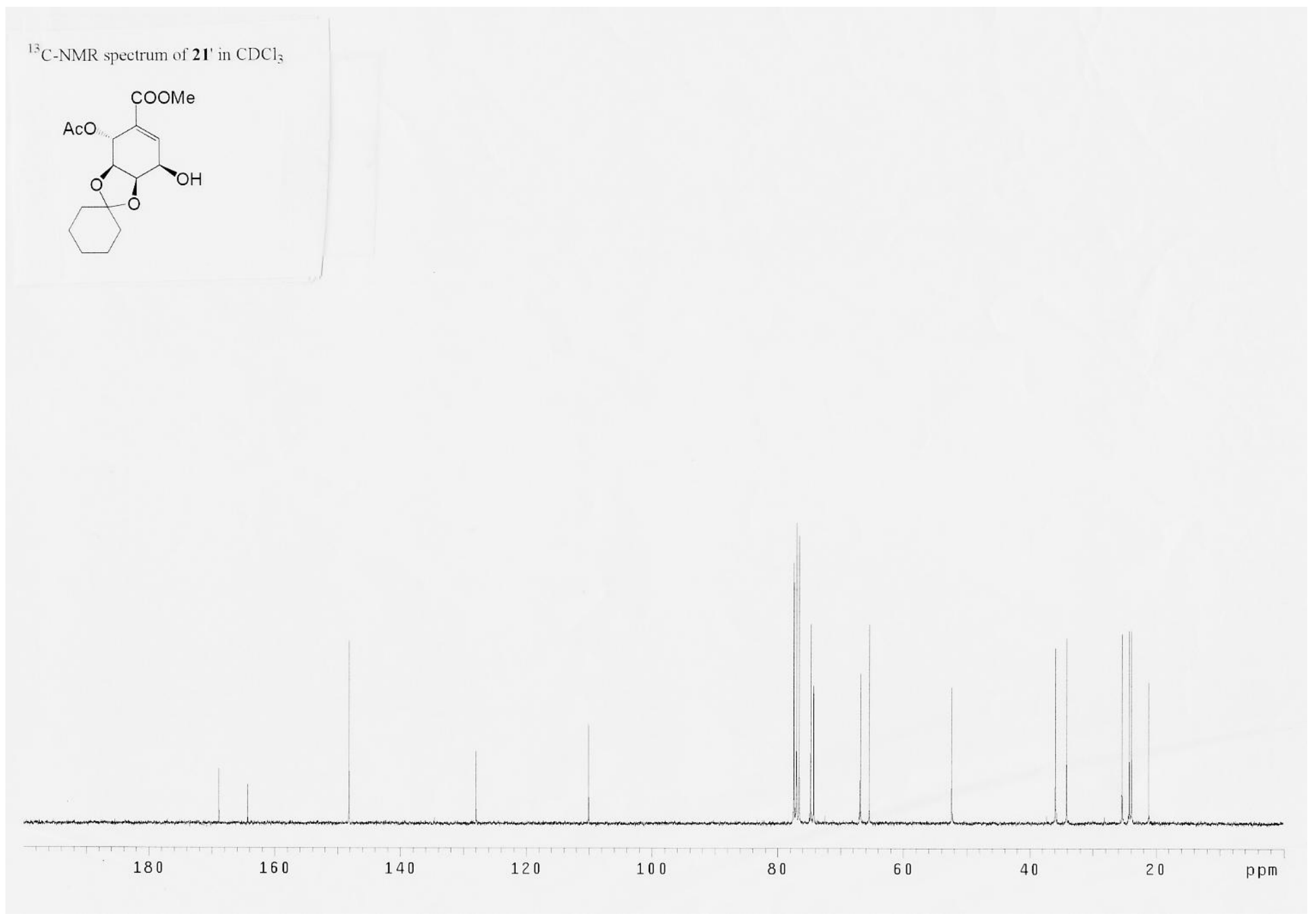

$75 \mathrm{MHz}$ 

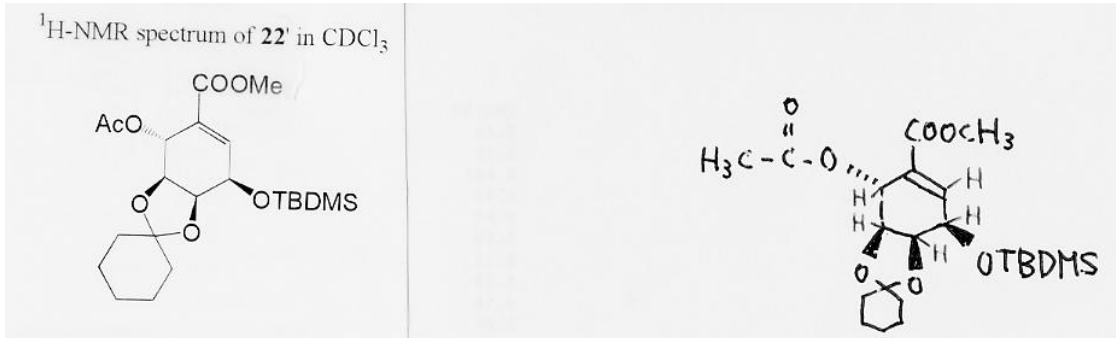

(pure)

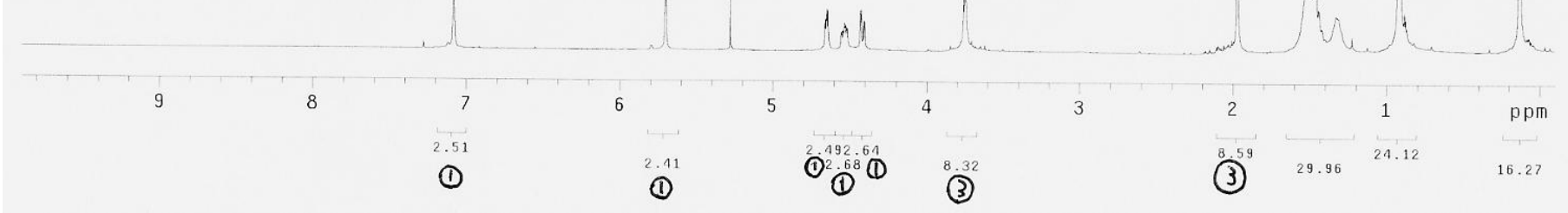

300MHz

S48 


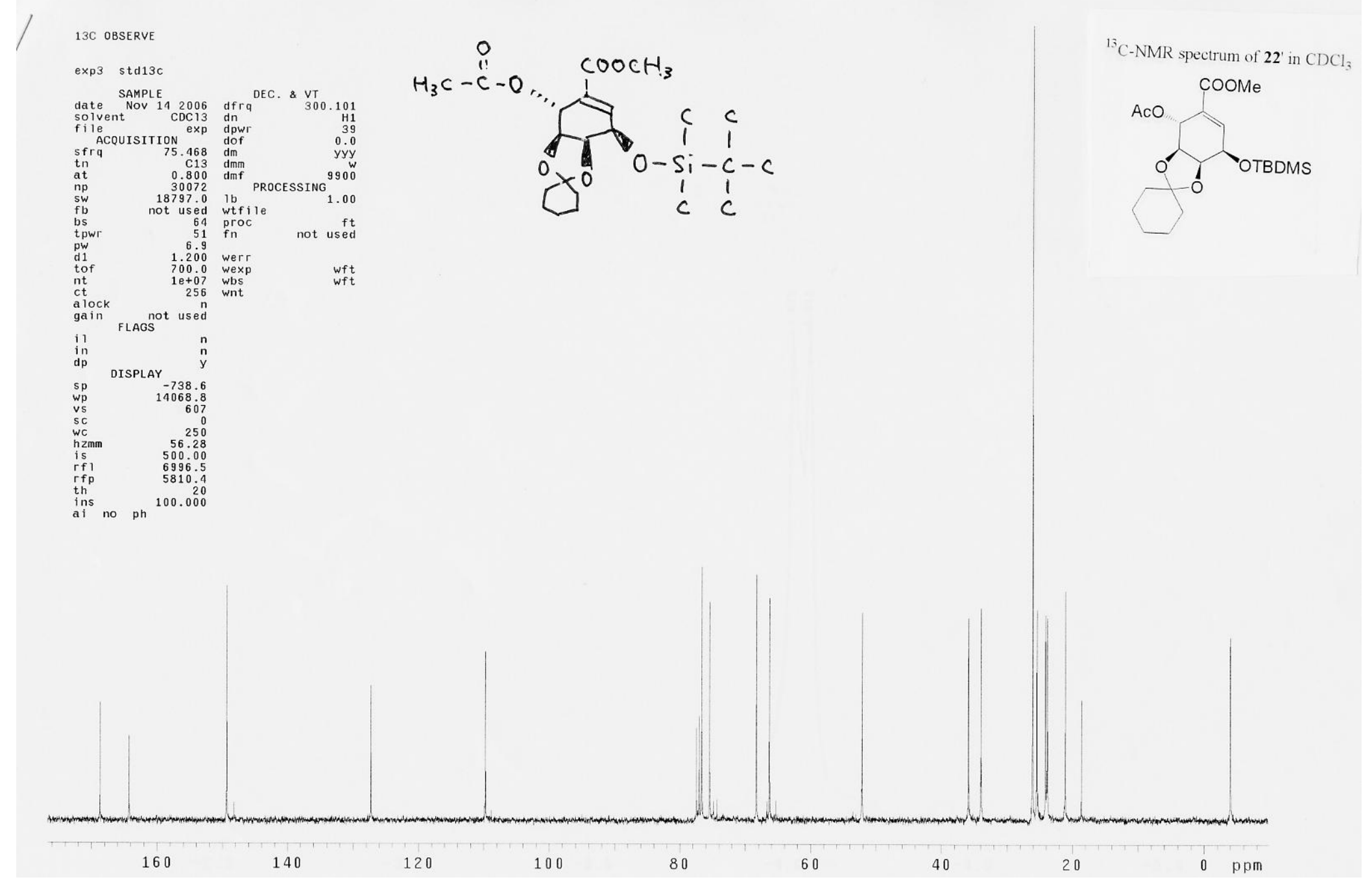

75MHz 


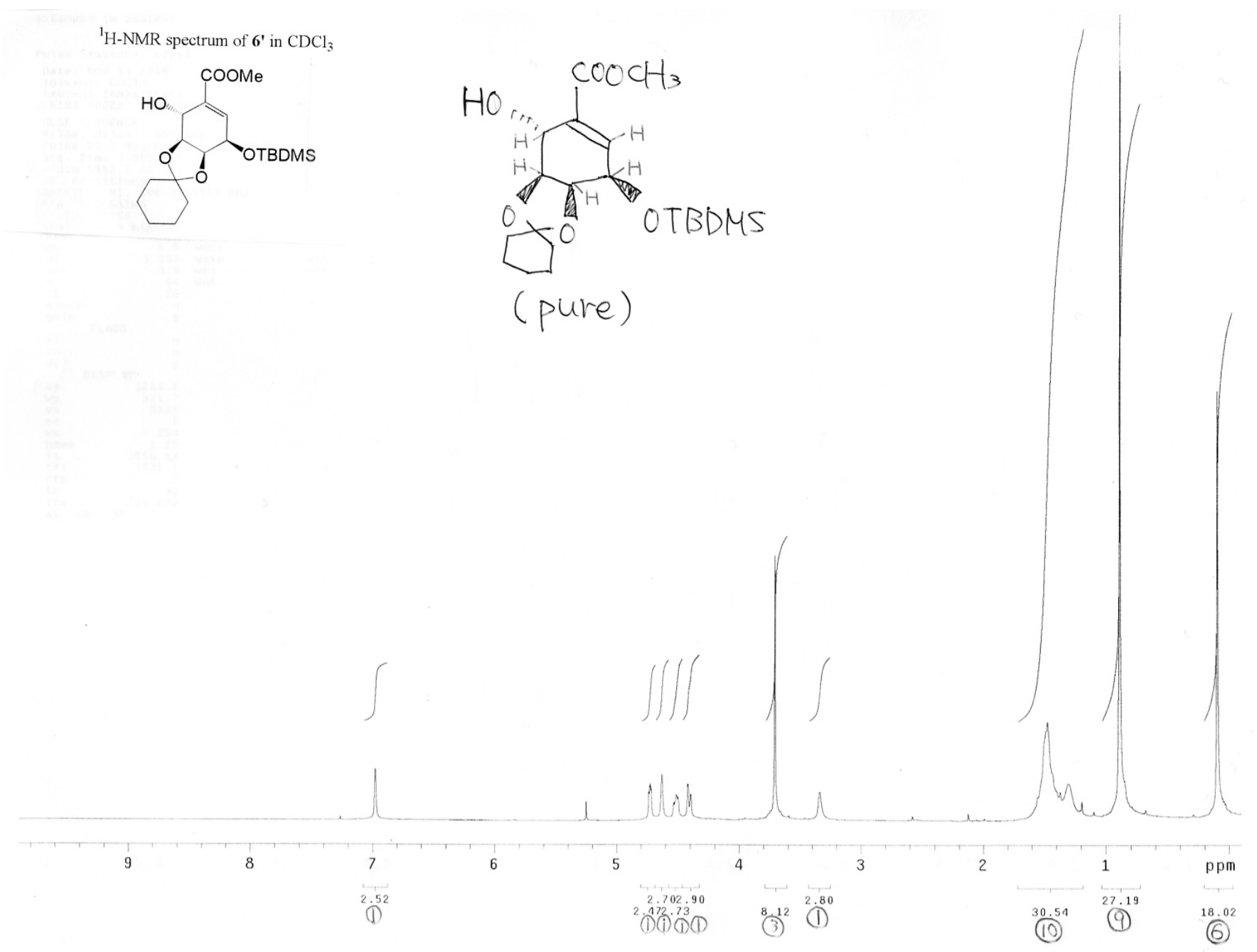

300MHz 


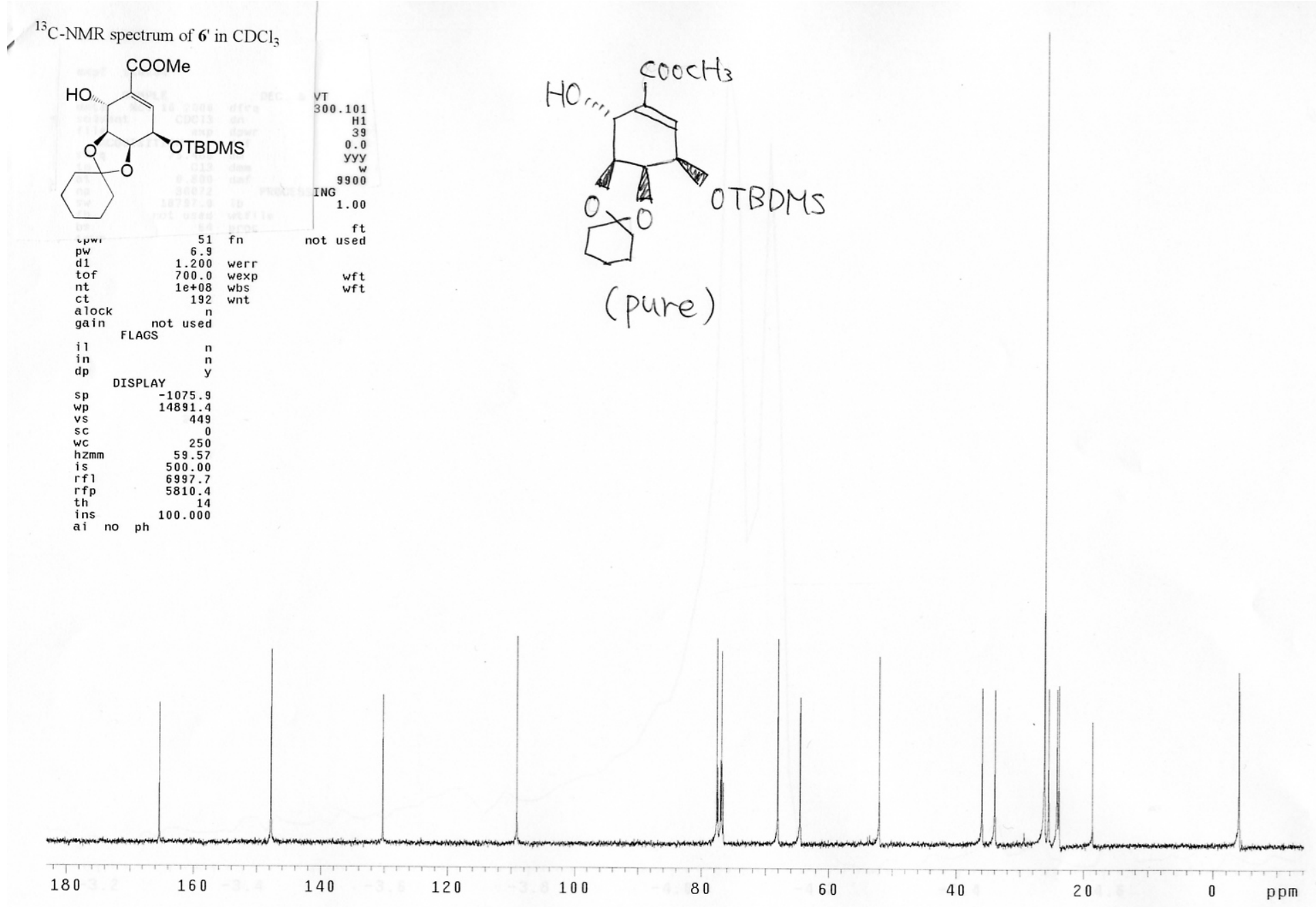

$75 \mathrm{MHz}$ 


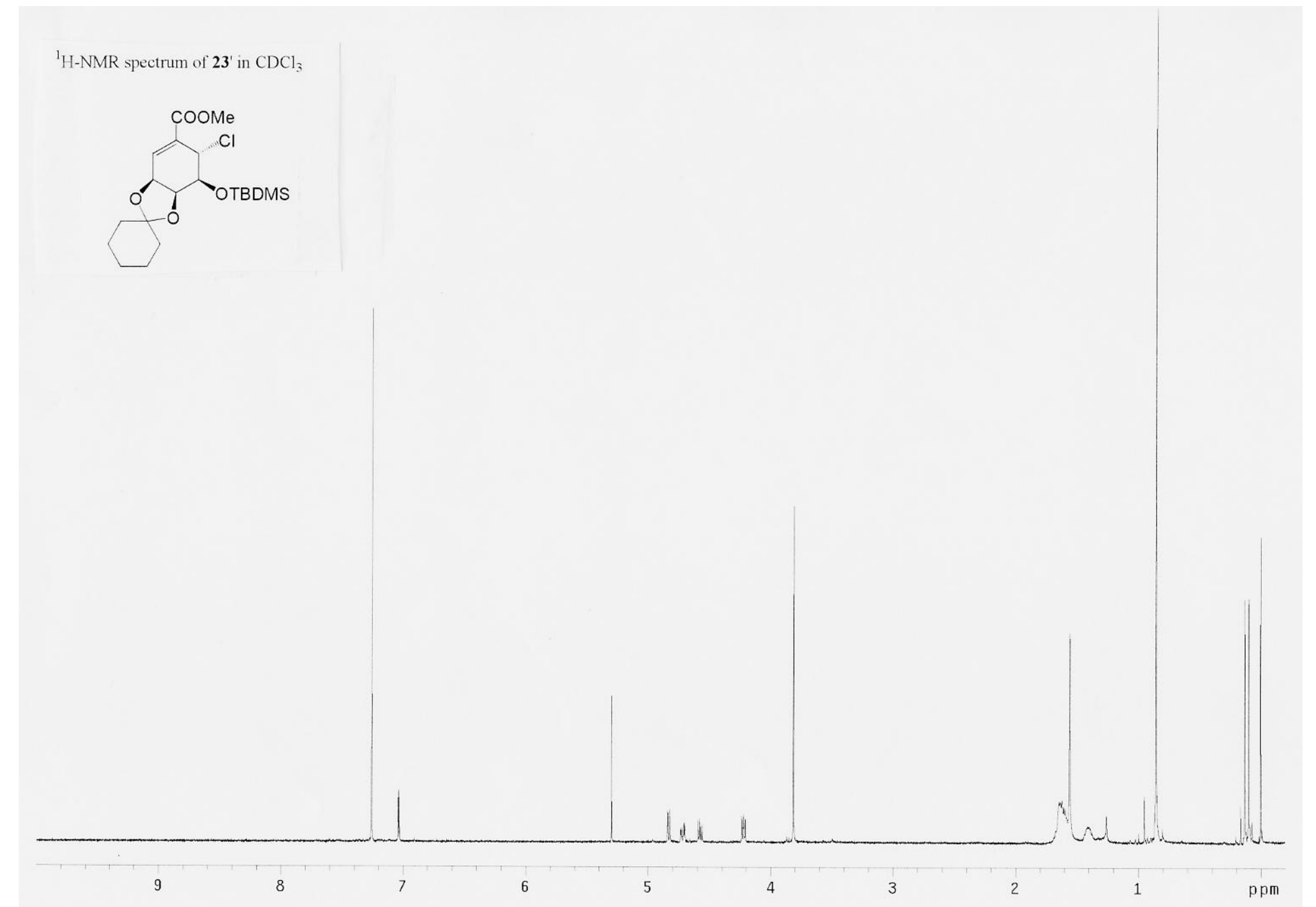

$300 \mathrm{MHz}$ 


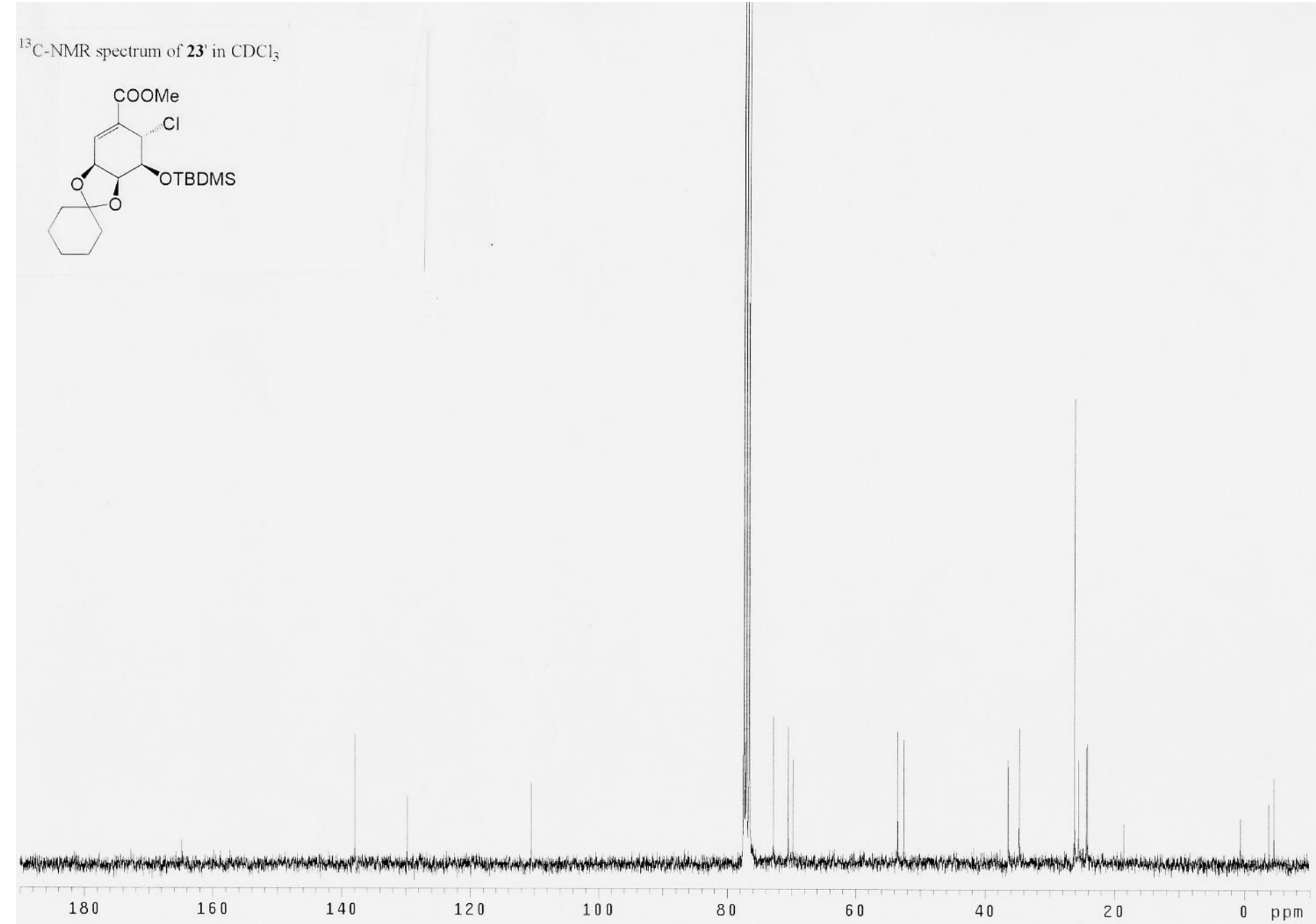

$75 \mathrm{MHz}$ 
Pulse Sequence: s2pu

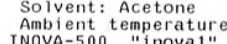

Relax. de lay $3.000 \mathrm{sec}$

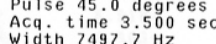

S reetitions
OBSERVE
H1, 499.

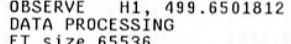

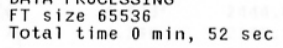

${ }^{1} \mathrm{H}$-NMR spectrum of $\mathbf{4}$ in acetone-d 6
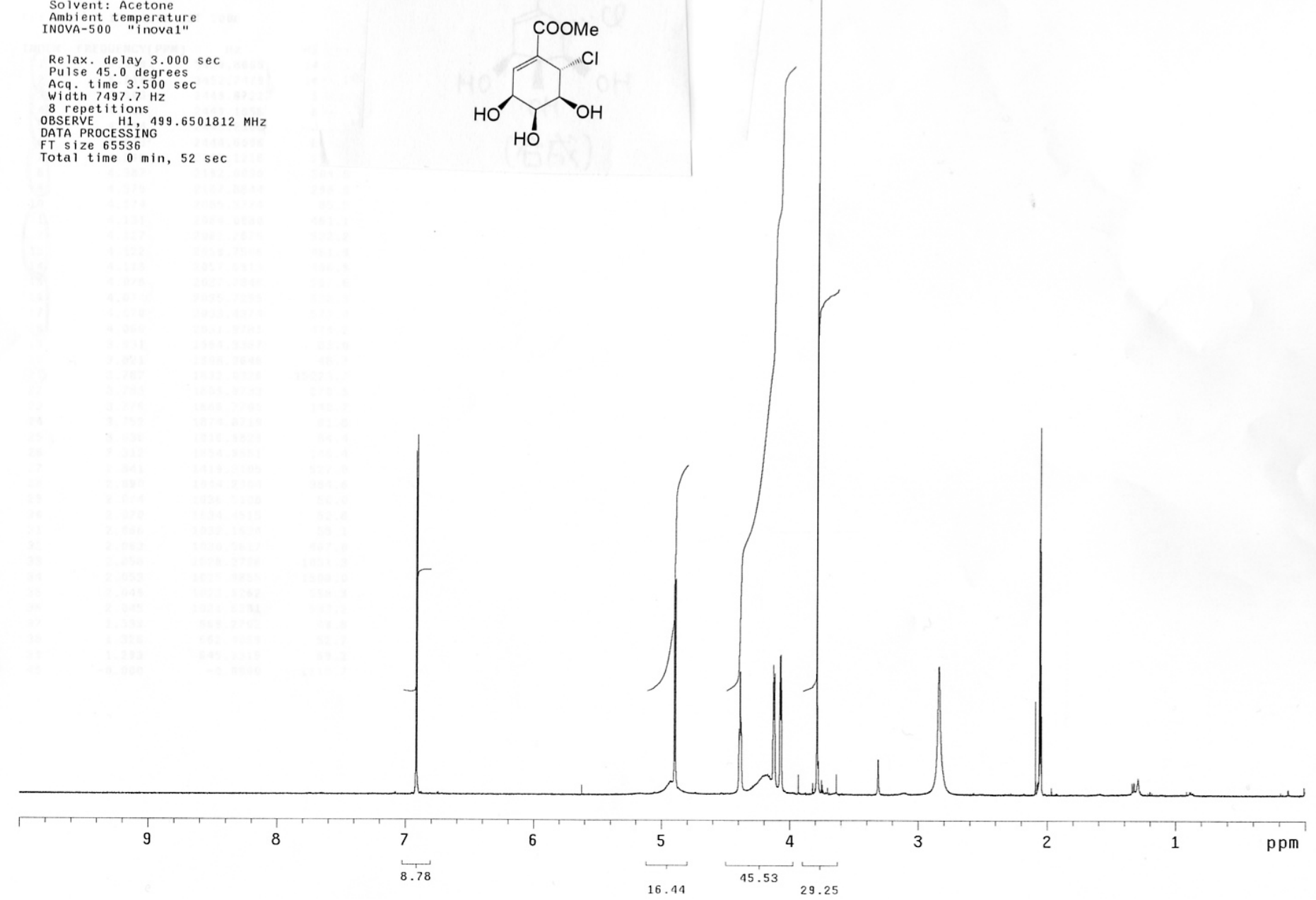

$500 \mathrm{MHz}$ 
0I-33-39 PLC-2 PLC

Pulse Sequence: s2pul
Solvent: Acetone

Ambient temperature
INOVA 500 "inova $1 "$

Relax. delay $1.500 \mathrm{sec}$
Pulse 45.0 degrees

Acq time $1.500 \mathrm{~s}$
Width $31421.8 \mathrm{~Hz}$

OBSERVE C13, 125.6370227 MHZ
DECOUPLE H1, 499.6526797 MHZ

Power 37 dB
continuous 1 on
GARP-1 modulated

DATA PROCESSING

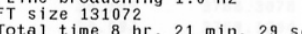

${ }^{13} \mathrm{C}-\mathrm{NMR}$ spectrum of $\mathbf{4}$ in acetone-d 6
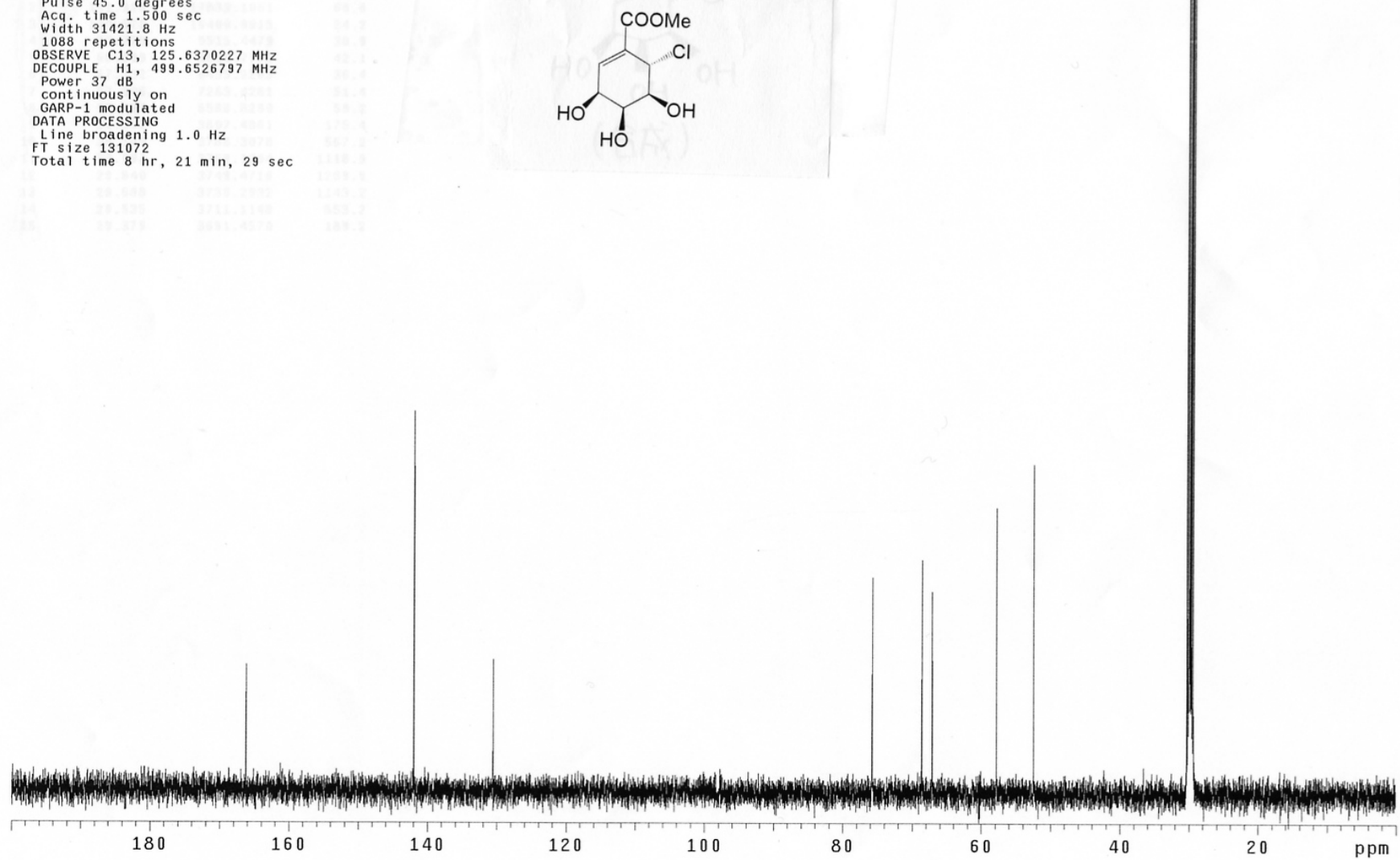

$125.6 \mathrm{MHz}$ 